\title{
Implications on Characterizing the Extremely Weak Sherwood Sandstone: Case of Slope Stability Analysis Using SRF at Two Oak Quarry in the UK
}

\author{
Tanja Sattler $\cdot$ Chrysothemis Paraskevopoulou $[$ (D)
}

Received: 3 August 2018/Accepted: 21 October 2018/Published online: 31 October 2018

(C) The Author(s) 2018

\begin{abstract}
In the past, engineering geology mainly focused on soil and hard rocks, with little attention paid specifically to weak/soft rocks, defined by a UCS below $25 \mathrm{MPa}$ (ISRM in Int $\mathrm{J}$ Rock Mech Min 18:85-110, 1981). Weak rock is an intermediate, which is difficult to analyze, and requires application of both soil and rock mechanics principles. The Sherwood Sandstone Group (SSG) in Nottinghamshire (UK) is often characterized as weak rock, containing extremely weak members, which display a UCS between 0.6 and $1 \mathrm{MPa}$ according to the definition from BS 5930:2015 (British Standards Institution 2015). Little research has been conducted on the locally extremely weak members of the Sherwood Sandstone Group, in particular the Nottingham Castle Sandstone Formation, and engineering projects within this unit can face major design challenges. This study aims at investigating the intact material, characterizing the SSG and analysing the stability of a slope in a quarry between two water-filled silt lagoons at the Two Oak Quarry, close to Mansfield. Laboratory testing, including UCS tests, triaxial tests, tensile tests and Slake Durability tests, is
\end{abstract}

T. Sattler

Baugeologisches Büro Bauer GmbH, Munich, Germany

e-mail: tanja.sattler@baugeologie.de

T. Sattler · C. Paraskevopoulou ( $\square)$

School of Earth and Environment, University of Leeds,

Leeds, UK

e-mail: c.paraskevopoulou@leeds.ac.uk conducted on the two geological units present on site, the Nottingham Castle Sandstone Formation and the Lenton Formation. From the analysis presented herein it is observed that the strength decreases as the degree of saturation increases, which can lead to a complete disintegration of the rock. In addition, the durability of the rock is determined, ranging from very low to moderately high, which has major implications on the longterm stability of the slope. The impact of the weathering on the long-term stability is difficult to establish and an estimation of the disintegration is conducted by comparing block sizes. A structural assessment confirms that failure along discontinuities is possible and requires further investigation. The Finite Element Analysis and the Limit Equilibrium Method are used for the assessment of the stability. Since similar factor of safety (FoS) are determined, both methods are considered applicable to the project, with limitations being detected when modelling discontinuities, impacting the design and the FoS. A suitable slope geometry is proposed, based on the intact material properties, the weathering characteristics, the heterogeneity of the material and structural features.

Keywords Geotechnical characterization - Slope stability · Quarry stability · Weak rock masses · Sherwood Sandstone · Water-filled silt lagoons 


\section{Introduction}

Slope stability is a major challenge which engineers and researchers are confronted with. Difficult ground conditions can significantly impact the stability and complicate the design process. The assessment of the geomechanically behaviour of weak rock masses is paramount, since they strongly influence and commonly govern the stability of slopes. It must be recognised that the transition and distinction between soil and rock is often not straightforward. Weak rocks are an intermediate between soil and hard rocks. Neither soil nor rock mechanics principles are fully applicable and the highly variable behaviour of weak rock, commonly results in inadequate sampling, testing and classification and subsequently either inadequate or overly conservative design. A major difference to hard rock is that disintegration is possible within short time periods in the presence of water and due to climatic changes (Nickmann et al. 2006).

The site under investigation is a quarry in extremely weak formation. With the proposed slope being the subdivision between two water-filled lagoons, it is self-explanatory that an understanding of the behaviour of weak rock is crucial. This research aims at providing information on the behaviour of weak Sherwood Sandstone, contributing to quantify the lower bound strength of the Sherwood Sandstone Group (SSG) in Nottinghamshire while assessing its influence on engineering projects. To ultimately determine an adequate geometry for the slope with a design life of 30 years, a geotechnical model is established based on strength properties determined from laboratory testing and site investigation, including structural features and weathering characteristics. This model is then used to assess and verify the preliminary layout of the slope using both continuum and pseudo-discontinuum models and assessing the applicability of the conventional Limit Equilibrium Method (LEM) and more sophisticated Finite Element Analysis (FEA) for weak rock masses.

The investigation is carried out at the Two Oak Quarry (Grid Reference: SK53866 56753), situated about $15 \mathrm{~km}$ north of Nottingham, UK (Fig. 1a). The relevant areas of the TOQ are shown in Fig. 1b).

\section{Background and Area of Interest Overview}

\subsection{Characteristics of Weak Rock}

The term "weak rock" is commonly used for both rock material itself and rock masses. The two main reasons for weak rock material are poor bonding and weathered components. The upper and lower boundary for "weak rock" is not consistently defined. Several different classifications exist. According to the British Standard BS EN ISO 14689-1:2003 Part 1 (British Standards Institution 2003) and the ISRM (1981) rocks with a UCS of 5-25 MPa are classified as weak rocks, with very weak rocks ranging from 1 to $5 \mathrm{MPa}$, and the compressive strength of extremely weak rocks is less than $1 \mathrm{MPa}$. In BS EN ISO 14689-1:2003 Part 1 (British Standards Institution 2003). As set out by BS 5930:2015, materials with an UCS between 0.6 and 1.0 MPa are classified as extremely weak rock. Hard rock and soil mechanic principles have only limited applicability to weak rock because it is an intermediate member. The main difference between weak and hard rock, is that weakening and disintegration of weak rocks over short periods of time due to climatic and moisture content changes is possible (Nickmann et al. 2006).

Several authors (Freitas 1990; Nickmann et al. 2006) describe problems regarding suitable sampling and testing methods of weak rock. These include mechanical impact on the rock, leading to disturbance and weakening of the material (Freitas 1990). Hence, it is not the intact rock properties which are determined in the laboratory. For the laboratory testing, no standardized testing program is available (Nickmann et al. 2006). Materials showing strengths towards the upper end of the spectrum are preferably tested according to rock mechanic principles, whereas for specimens situated towards the lower end, soil mechanic principles may be more suitable.

\subsection{Overview of the Area of Interest}

\subsubsection{Geological Setting}

A geological overview of the area is shown in Fig. 2. The rocks generally strike north-south and usually dip around $1^{\circ}-2^{\circ}$, in places up to $4^{\circ}$, to the East (Allen et al. 1997). Hence units older than the Sherwood 

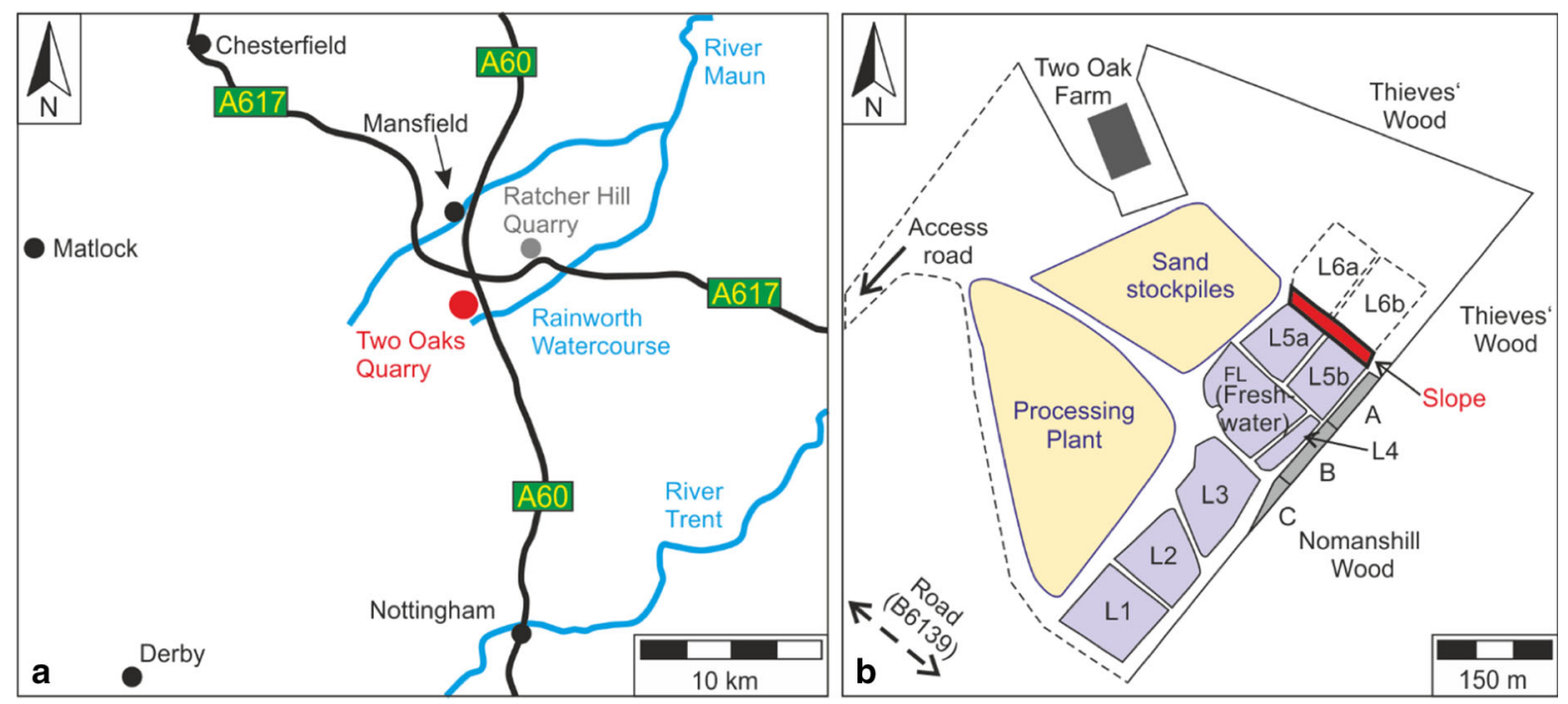

Fig. 1 a Simplified overview of the region (modified after Ordnance Survey 2017); b simplified site plan (modified after Greenfield Associates 2013) showing the Lagoons (L): solid

lines show excavated and filled lagoons; dashed lines indicate planned lagoons, which have not been excavated
Fig. 2 Geologic overview; dashed line indicates extent of Sheet Memoir 112Chesterfield (modified after BGS 2017a); minor quaternary deposits not displayed

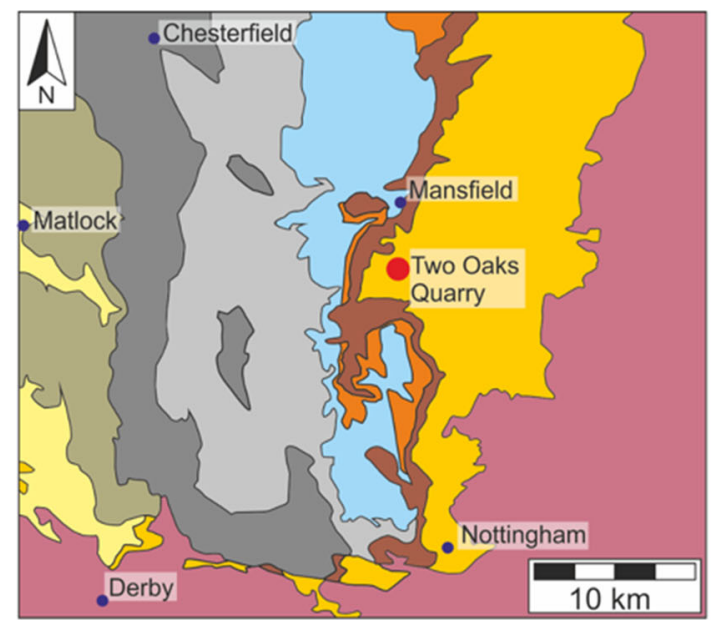

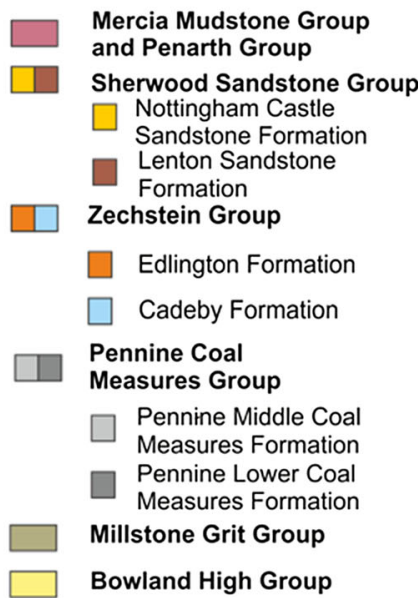

Sandstone Group crop out to the West of the site, and younger units surface to the East.

The relevant unit for this study, the SSG (Late Permian to Mid Triassic Period) was mainly deposited in actively subsiding continental basins limited by faults. The fluviatile deposition mechanism is responsible for fining-upwards cycles, cross-bedding and the deposition of thin mudstone beds (Smith et al. 1967). In the East Midlands, the Sherwood Sandstone Group (SSG) is divided into the Lenton Formation (LF) which is overlain by the Nottingham Castle Sandstone Formation (NCSF) (Ambrose et al. 2014). The thickness of the LF varies between 12 and $70 \mathrm{~m}$ according to the BGS (2017b) and the NCSF shows a maximum thickness of approximately $150 \mathrm{~m}$ around Nottingham (Bell et al. 2009).

\subsubsection{Sherwood Sandstone Group (SSG)}

According to the BGS (2017a) the SSG is characterised as a very weak to medium strong, thinly to thickly bedded, fine to coarse grained SANDSTONE with medium to widely spaced discontinuities. The sandstone can contain pebbly layers, which are very 
weak to strong coarse-grained CONGLOMERATE or BRECCIA with angular clasts. Yates (1992) recognises that layers of sand are also present. Weak zones in the SSG are attributed to poor cementation during diagenesis, weathering and dissolution processes, as well as to the impacts of glacial and periglacial activity. Yates (1992) recommends that very weak or cohesion-less layers are analysed as discontinuities. The strength of the SSG is strongly influenced by the particle size, the porosity and the moisture content (Bell et al. 2009). For the NCSF the strength reduction due to a high degree of saturation is significant, because of the high porosity. A summary of the engineering properties of the SSG from Nottinghamshire is given in Table 1.

As shown in Table 1, the strength of the SSG decreases by $30-40 \%$ when the samples are saturated, and testing specimens in a dry state can lead to an overestimation of the strength. Hence, it is recommended to test samples in a saturated state (Yates 1992; Dobereiner and Freitas 1986). Saturating friable sandstone is often difficult as samples tend to disintegrate during saturation. Dobereiner and Freitas (1986) define the boundary between sand and sandstone by disintegration during saturation. If samples disintegrate during saturation the strength is defined as less than 0.5 MPa and it classifies as sand. The poor cementation of the material makes it prone to disintegration when mechanically impacted. Therefore, the distinction between drilling-induced fractures and natural discontinuities is often challenging (Spink and Norbury 1990). Hence, it is often described as soil, even though outcrops show that it clearly is a rock and shall be addressed using rock terminology (Spink and Norbury 1990).

Slope stability issues in SSG outcrops are rare in Nottinghamshire (Pennington et al. 2009). According to Bell et al. (2009), rockfalls and sliding occur in the SSG. Uncertainties regarding the failure mechanism are caused by the strength of the discontinuities not being significantly lower than the intact rock strength (Spink and Norbury 1990). According to Spink and Norbury (1990) the weathering of the SSG is defined by the gradual disintegration from competent sandstone into loose sand.

\subsubsection{Site Investigation}

A 2-day site investigation was carried out involving field testing and sampling. The slope under investigation is located between L5 and L6 with the geometry is shown in Figure. The crest of lagoon L5a/b is at an approximate elevation of $140 \mathrm{~m}$ AOD and the crest of lagoons L6a/b is planned to reach $150 \mathrm{~m} \mathrm{AOD.} \mathrm{The}$

Table 1 Engineering properties of the SSG in Nottinghamshire (Bell and Culshaw 1990)

\begin{tabular}{lll}
\hline Parameter & NCSF mean $( \pm$ SD) & LF mean $( \pm$ SD) \\
\hline Particle size analysis & Medium-grained & Fine grained \\
Mean grain size $(\mathrm{mm})$ & $0.24( \pm 0.03)$ & $0.19( \pm 0.08)$ \\
UCS $(\mathrm{MPa})$ & $11.8( \pm 4.1)$ & $14.7( \pm 1.8)$ \\
UCS (saturated) $(\mathrm{MPa})$ & $7.0( \pm 2.9)$ & $9.5( \pm 2.3)$ \\
Young's modulus, dry* $(\mathrm{GPa})$ & $6.16( \pm 1.98)$ & $7.96( \pm 0.80)$ \\
Young's modulus, saturated* $(\mathrm{GPa})$ & $3.16( \pm 1.39)$ & $4.53( \pm 0.47)$ \\
Poisson's ratio $(\mathrm{dry})(-)$ & $0.23( \pm 0.05)$ & $0.25( \pm 0.04)$ \\
Tensile strength $(\mathrm{Brazilian})(\mathrm{MPa})$ & $0.74( \pm 0.45)$ & $0.85( \pm 0.32)$ \\
Dry density $\left(\mathrm{Mg} / \mathrm{m}^{3}\right)$ & $1.83( \pm 0.05)$ & $1.94( \pm 0.04)$ \\
Saturated density $\left(\mathrm{Mg} / \mathrm{m}^{3}\right)$ & $2.09( \pm 0.04)$ & $2.13( \pm 0.07)$ \\
Saturation moisture content $(\%)$ & $14.2( \pm 1.1)$ & $12.5( \pm 0.8)$ \\
Effective porosity $(\%)$ & $26.2( \pm 1.9)$ & $23.5( \pm 0.7)$ \\
Absolute porosity $(\%)$ & $31.8( \pm 1.9)$ & $26.9( \pm 1.6)$ \\
Coefficient of permeability $(\mathrm{m} / \mathrm{s})$ & Vert.: $2.5 \times 10^{-7}\left( \pm 0.6 \times 10^{-7}\right)$ & Vert.: $1.3 \times 10^{-7}\left( \pm 0.6 \times 10^{-7}\right)$ \\
& Horiz.: $3.8 \times 10^{-7}\left( \pm 1.2 \times 10^{-7}\right)$ & Horiz.: $1.9 \times 10^{-7}(-)$ \\
\hline
\end{tabular}

*Tangential moduli taken at 50\% ultimate strength 
maximum water level in lagoons L5a/b is at $139 \mathrm{~m}$ AOD and for lagoon $6 \mathrm{a} / \mathrm{b}$ it is at $149 \mathrm{~m} \mathrm{AOD}$, with the base of L5 at $129 \mathrm{~m} \mathrm{AOD}$ and L6 at $135 \mathrm{~m}$ AOD.

The slope was not accessible and the investigation is carried out on the south-eastern slope (Fig. 3). Due to no coring equipment being available loose block samples are taken from the ground. Blocks from different locations, which have been exposed for different amounts of time are taken, to assess the impact of weathering (Areas A/B/C in Fig. 3). The LF is present at the bottom of the lagoons but is not accessible. Hence samples from the LF (Sampling ID: L) are taken from a stockpile. Since the block samples do not contain the natural moisture content, these samples are referred to as "air-dry".

\section{Laboratory Testing}

The laboratory tests (Table 2) are conducted in accordance with the ISRM Suggested Methods (ISRM 2007) and variations from the recommended procedure are reported in each section.

\subsection{Sample Preparation}

The samples are cored in the laboratory facilities of the University of Leeds using a Richmond coring rig with a 38-mm (external diameter) smooth drill bit and airflush because of the sensitivity of the material to water. A smaller diameter drill bit is chosen instead of the preferred diameter of $54 \mathrm{~mm}$ outlined by the ISRM (2007) to be able to use equipment specified for soil testing, in order accurately record the strength of the weak rock. Intact core is gained from approximately $50 \%$ of the samples, possibly owing to the heterogeneity of the material, its generally weak nature or poor cementation. The ends of the specimens are sawed, but grinding is not possible due to the friability. Whenever the bedding planes are visible, the coring direction is perpendicular to bedding. Water content, saturation and porosity are recorded for each sample, since they strongly influence the strength of weak rock (Oliveira 1990; Dobereiner and Freitas 1986). No desiccator is used for cooling the samples. The porosity is determined by the saturation and buoyancy technique (Franklin et al. 1979) and for each block sample, two specimens with a minimum mass of $50 \mathrm{~g}$ are tested. The saturated, bulk and dry density are reported for each UCS test series. The resistance of rock against weakening and disintegration over time is assessed using the Slake Durability Test, with tap water being used as slaking fluid.

\subsection{Unconfined Compressive Strength (UCS) Testing}

A total of 30 UCS tests shall be conducted with 5 series each for the NCSF and the LF. A series consists of 3 specimens, tested at different degrees of saturation: oven-dry, air-dry and fully saturated. Due to insufficient core recovery, only 4 series are conducted for each formation. The letter of the sample ID indicates the tested state:

- OD: oven-dry (dried at $105{ }^{\circ} \mathrm{C}$ for more than $24 \mathrm{~h}$ )

- AD: air-dry (stored in a sealed plastic bag until testing)

- S: saturated [vacuum saturated for more than $2 \mathrm{~h}$ (Dobereiner and Freitas 1986)]

The UCS tests are conducted with a MAND Universal Compression and Tensile Tension Testing Machine and a preload of $25 \mathrm{~N}$ is applied. A loading rate of $0.1 \mathrm{~mm} / \mathrm{min}$ is chosen to achieve failure within 5-10 min. This is similar to the loading rate of $0.1 \mathrm{kN} /$ min used by Yates (1992) for weak sandstone, in order to ensure full dissipation of excess pore pressure while complying with the ISRM Guidelines (Bieniawski et al. 1979). LVDTs are used to measure the axial and
Fig. 3 a Cross section showing the layout of slope under investigation; horizontally not to scale; b plan view of the relevant area of study
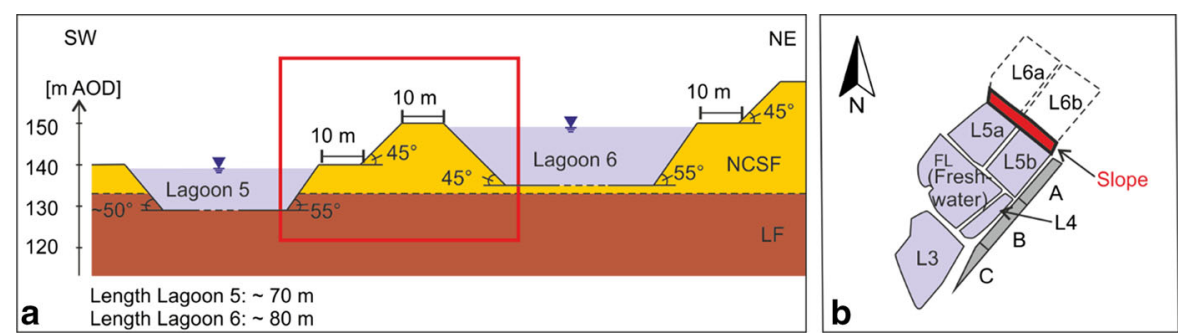
Table 2 Summary of testing programme conducted according the ISRM Guidelines

\begin{tabular}{lccc}
\hline Test & NCSF (conducted, valid) & LF (conducted, valid) & References \\
\hline Water content & $5(4)$ & $5(4)$ & Franklin et al. (1979) \\
Density (dry, bulk, saturated) & $15(12)$ & $15(12)$ & Franklin et al. (1979) \\
Porosity & $5\left(6 \times 2^{\mathrm{a}}\right)$ & $5\left(4 \times 2^{\mathrm{a}}\right)$ & Franklin et al. (1979) \\
UCS test + deformability & $15(12)$ & $15(12)$ & Bieniawski et al. (1979) \\
Triaxial multistage tests (3 stages) & $5(3$ Multi-stage, 3 single-stage) & $5(3)$ & Franklin (1983) \\
Brazilian test & $10\left(3 \times 2^{\mathrm{a}}\right)$ & $10\left(3 \times 2^{\mathrm{a}}\right)$ & Bieniawski and Hawkes (1978) \\
Slake durability & $3(3)$ & $3(3)$ & Franklin et al. (1979) \\
\hline
\end{tabular}

${ }^{\mathrm{a}} \times 2$ Indicates that 2 specimens from the same sample were tested and an average value determined

lateral displacement. Young's Moduli are determined over a stress range of $30-60 \%$ peak stress.

\subsection{Triaxial Compressive Testing}

Triaxial testing is conducted to determine the failure envelope of the rock and the parameters c' and $\varphi$ ' for the slope stability analysis. Since only a limited number of samples is available multi-stage tests are conducted. The LF tests are conducted in the same apparatus as the UCS tests, whereas the NCSF samples are tested in a Tritech 50 Compression Testing Machine, because of their low strength. Undrained testing with pore pressure measurements is the preferred testing method, but equipment restrictions only allow for quick undrained testing. As for the UCS test, a loading rate of $0.1 \mathrm{~mm} / \mathrm{min}$ is used.

The data is analysed with the software RocData 5.0 (Rocscience 2017) and the Generalized Hoek-Brown (HB) Failure Criterion is used for the determination of the peak strength parameters (Hoek et al. 2002), since Yates (1992) describes the failure envelope of the SSG as strongly curvilinear. The confining pressures are chosen to be an adequate representation of the existing stress field at the required depth (Yates 1992; Hoek et al. 2002). To compare the results to Yates (1992), a maximum $\sigma_{3}$ of $1 \mathrm{MPa}$ is applied. This stress range covers a depth range where both units are encountered. In the following step, this parameter was refined to the actual slope height of $21 \mathrm{~m}$ to apply adequate values for the slope design.

\subsection{Brazilian (Indirect) Tensile Testing}

The indirect tensile strength is determined by six Brazilian tests being conducted on each unit to define the tensile cut-off. Instead of curved jaws, straight platens are used. The limited availability of core leads to the test being conducted on pieces of core with the same orientation as the UCS and triaxial test.

\subsection{Laboratory Testing Results}

An overview of the laboratory testing results is displayed in Table 3.

\subsubsection{UCS Testing Results}

The stress-strain curves for the UCS tests is shown in Fig. 4. Fluctuations of the curves are due to the sensitivity of the equipment. Figure 4 a presents the brittle behaviour of the LF, which is not as distinct for the NCSF shown in Fig. 4b. The lateral strain curves (not displayed) show an almost vertical slope, indicating little lateral movement.

The correlation of the UCS with the moisture content (Fig. 5, semi-logarithmic scale) displays high UCS values for dry samples from the LF, with a strength decline seen with an increasing moisture content, whereas peak values for the NCSF are reached in an air-dry condition and the saturation moisture content of the Nottingham Castle Formation is around $14 \%$. The LF shows a significantly lower saturation moisture content between 3 and $7 \%$ and sample L1 displays a higher value of $13 \%$.

Different failure modes are also noticeable: Axial splitting and shear failure is observed for both units 
Table 3 Summary of results from laboratory testing

\begin{tabular}{|c|c|c|c|c|}
\hline & \multicolumn{2}{|l|}{ NCSF } & \multicolumn{2}{|l|}{ LF } \\
\hline & Mean value & $\pm \mathrm{SD}$ & Mean value & $\pm \mathrm{SD}$ \\
\hline Dry density $\left(\mathrm{kg} / \mathrm{m}^{3}\right)$ & 1760 & \pm 34 & 2150 & \pm 171 \\
\hline Bulk density $\left(\mathrm{kg} / \mathrm{m}^{3}\right)$ & 1910 & \pm 30 & 2250 & \pm 157 \\
\hline Saturated density $\left(\mathrm{kg} / \mathrm{m}^{3}\right)$ & 2060 & \pm 44 & 2320 & \pm 117 \\
\hline Moisture content $(\%)^{\mathrm{a}}$ & 6.4 & \pm 2.3 & 3.2 & \pm 1.8 \\
\hline Porosity (\%) & 30.7 & \pm 0.9 & 18.5 & \pm 5.4 \\
\hline UCS oven-dry (MPa) & 0.516 & \pm 0.669 & 26.0 & \pm 12.3 \\
\hline UCS air-dry (MPa) & 1.53 & \pm 0.822 & 15.4 & \pm 11.0 \\
\hline UCS saturated $(\mathrm{MPa})$ & 0.776 & \pm 0.498 & 15.3 & \pm 12.1 \\
\hline Young's modulus oven-dry (MPa) & 155 & \pm 143 & 4597 & \pm 2433 \\
\hline Young's modulus airdry (MPa) & 257 & \pm 133 & 3194 & \pm 2400 \\
\hline Young's modulus saturated* (MPa) & 258 & \pm 164 & 3389 & \pm 2993 \\
\hline Poisson's ratio airdry, calculated & 0.119 & \pm 0.0551 & 0.0820 & - \\
\hline Tensile strength (MPa) & 0.095 & \pm 0.036 & 0.243 & \pm 0.116 \\
\hline Slake durability (1st cycle durability; $\left.\mathrm{I}_{\mathrm{D} 1}\right)$ ) & 4.6 & \pm 6.4 & 59.3 & \pm 34.8 \\
\hline Slake durability (2nd cycle durability; $\left.\mathrm{I}_{\mathrm{D} 2}\right)$ ) & 2.1 & \pm 2.9 & 51.5 & \pm 33.6 \\
\hline $\begin{array}{l}\text { Peak strength } \\
\mathrm{c}^{\prime}(\mathrm{MPa}) / \varphi^{\prime}\left(^{\circ}\right) \text {; for } \sigma 3 \max .=1 \mathrm{MPa}\end{array}$ & $0.39 \mathrm{MPa} / 37.78^{\circ}$ & - & $1.01 \mathrm{MPa} / 53.29^{\circ}$ & - \\
\hline $\begin{array}{l}\text { Peak strength } \\
\mathrm{c}^{\prime}(\mathrm{MPa}) / \varphi^{\prime}\left(^{\circ}\right) \text {; for } \sigma 3 \text { max. determined from } \\
\text { slope height }=21 \mathrm{~m}\end{array}$ & $\begin{array}{c}0.29 \mathrm{MPa} / 45.59^{\circ}(\sigma 3 \\
\max =0.32 \mathrm{MPa})\end{array}$ & - & $\begin{array}{c}0.88 \mathrm{MPa} /{ }^{\circ} 57.47(\sigma 3 \\
\max =0.43 \mathrm{MPa})\end{array}$ & - \\
\hline $\begin{array}{l}\text { Residual strength } \\
\mathrm{c}_{\mathrm{r}}(\mathrm{MPa}) / \varphi_{\mathrm{b}}\left({ }^{\circ}\right)^{\mathrm{b}}\end{array}$ & $0.03 / 38.7$ to $0.01 / 42.54$ & - & $0.27 / 42.89$ to $0.42 / 49.31$ & - \\
\hline
\end{tabular}

${ }^{\mathrm{a}}$ Moisture content of air-dry samples; does not correspond to natural moisture content

${ }^{\mathrm{b}}$ Full range given for residual parameters, since lower bound values are necessary for the slope analysis

(Fig. 6). $50 \%$ of the NCSF and $17 \%$ of the LF specimens show axial splitting, with the remaining samples shearing along an inclined plane.

\subsubsection{Triaxial Testing Results}

In general, the multi-stage tests work very well for the LF, but only to a limited extent for the NCSF. The software to log the data does not have an appropriate resolution to confidently see the curve levelling off, leading to failure of the sample during the first stage. The failure envelopes area shown in Fig. 7 and the peak strength and residual properties from the triaxial tests are shown in Table 3.

\subsubsection{Brazilian Testing Results}

The results from the Brazilian tests are stated in Table 3 and shown in Fig. 8.

\subsection{Interpretation/Discussion of Laboratory Testing Results}

A comparison of the site-specific properties of the SSG at the TOQ compared to literature values around Nottingham is shown in Table 4.

The key findings from the laboratory testing are that the NCSF is an extremely weak rock, with an average UCS of 1.5 MPa in an air-dry state, which is reduced to $0.8 \mathrm{MPa}$ when saturated. With the boundary between sand and sandstone being specified by Dobereiner and Freitas (1986) at $0.5 \mathrm{MPa}$ in a saturated state, the material must be analysed as rock. 

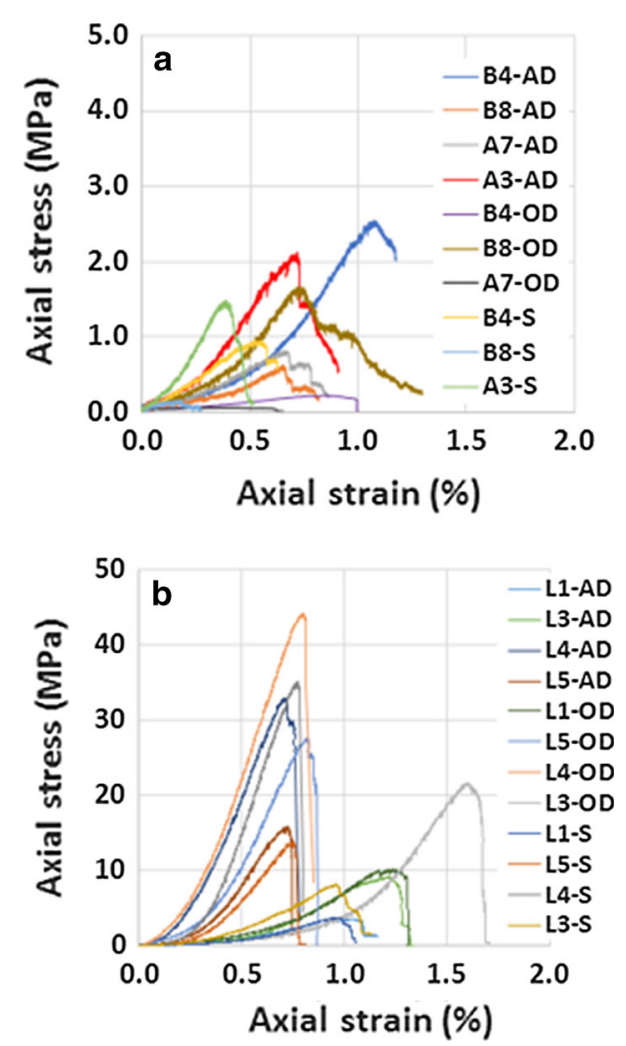

Fig. 4 a Stress strain curves from the UCS tests for the sampling series from the NCSF; letters in the sample ID indicate: (OD) oven-dry state, (AD) air-dry state, (S) saturated state; $\mathbf{b}$ stress-strain curves from the UCS tests for the sampling series from the LF; second digits indicate: (OD) oven-dry state, (AD) air-dry state, $(\mathrm{S})$ saturated state

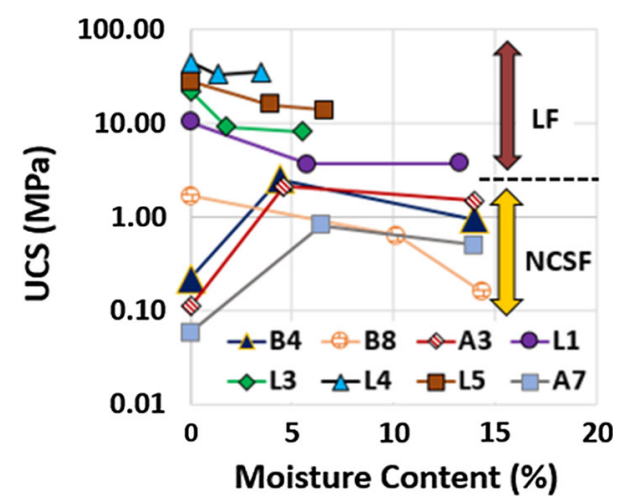

Fig. 5 Relationship between the UCS and moisture content for each sampling series from the NCSF and LF

The results from the UCS tests deviate significantly from literature values from around Nottingham (Bell and Culshaw 1990; Yates 1992) and show the high spatial variability of the NCSF. Furthermore, it is shown that the higher the degree of saturation is the lower the UCS. The decrease in strength of the NCSF of $35 \%$ upon saturation according to Bell et al. (2009) is also reflected in the test results and a loss of about $42 \%$ is observed in this study. A different trend displayed by some of the samples is attributed to end effects, since the friability of the samples does not allow the ends to be grinded. This does not represent the actual properties, with an uneven stress distribution causing early failure (Szczepanik et al. 2007). The influence of end effects is also shown by the failure mode, with axial splitting being observed. Axial splitting indicates failure governed by tensile stresses, due to end effects including platen friction (Johnston 1991). The obtained results from the UCS tests are compared to Yates's (1992), and Dobereiner and Freitas (1986) results in Fig. 9. The tested specimens from both the NCSF and LF show a lower strength at a constant saturation moisture content than the literature values. Sample $\mathrm{L} 1$ is believed to be from the transition zone between the two units (BGS 2017b) because of its intermediate strength.

The research confirms that the NCSF has a very low durability, disintegrates easily and is prone to weathering. The high porosity and poor cementation, as observed in this research work for the NCSF, adversely affect the durability (Dhakal et al. 2004) and is responsible for the fast disintegration of the samples. The LF shows a very low to medium high durability. The samples with the highest UCS show the highest durability and vice versa, which agrees with correlations between the UCS and the durability found by Yagiz (2011). The applicability of the Slake Durability test is questioned due to the mechanical impact on the samples, which does not represent the in situ properties adequately (Nickmann et al. 2006).

The strength of the intact rock is determined by triaxial tests, with the NCSF showing a cohesion of $0.29 \mathrm{MPa}$ and an angle of friction of $46^{\circ}$ on average. The triaxial compression test results from the NCSF for $\sigma 3$ max. = $1 \mathrm{MPa}$ are comparable to research by Yates (1992), who states an effective friction angle of $44^{\circ}$ to $55^{\circ}$ and an effective cohesion of 0.14-2.18 MPa. When applying the design chart by Yates to the researched slope, for a saturated UCS of $0.8 \mathrm{MPa}$, a friction angle $45^{\circ}$ and a cohesion of $0.15 \mathrm{MPa}$ is recommended. This confirms that the values determined from laboratory testing are also applicable to the slope when the rock is saturated. The 
B8-3

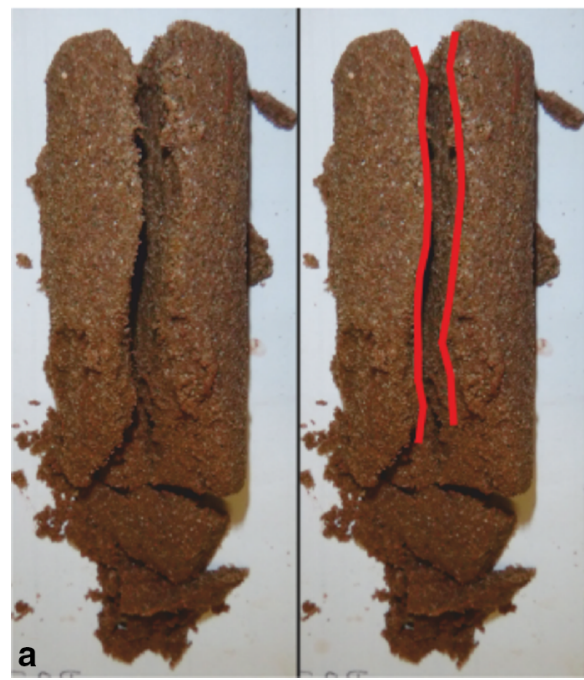

L4-1

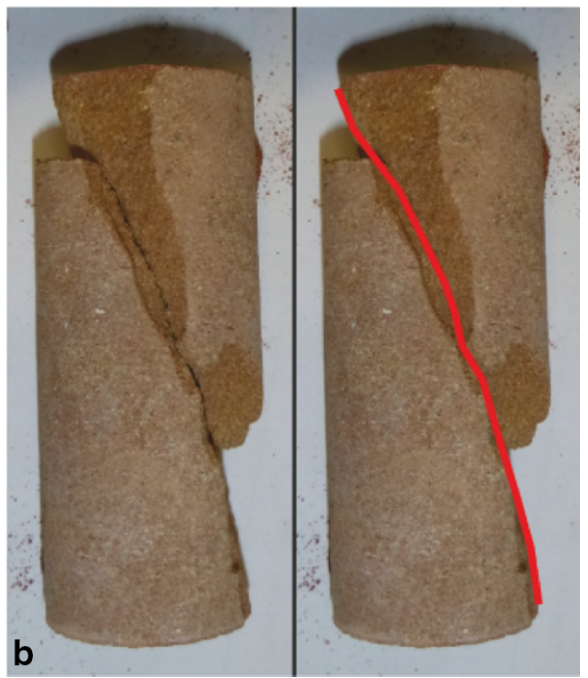

Fig. 6 Observed modes of failure; left: axial splitting; right: shear failure

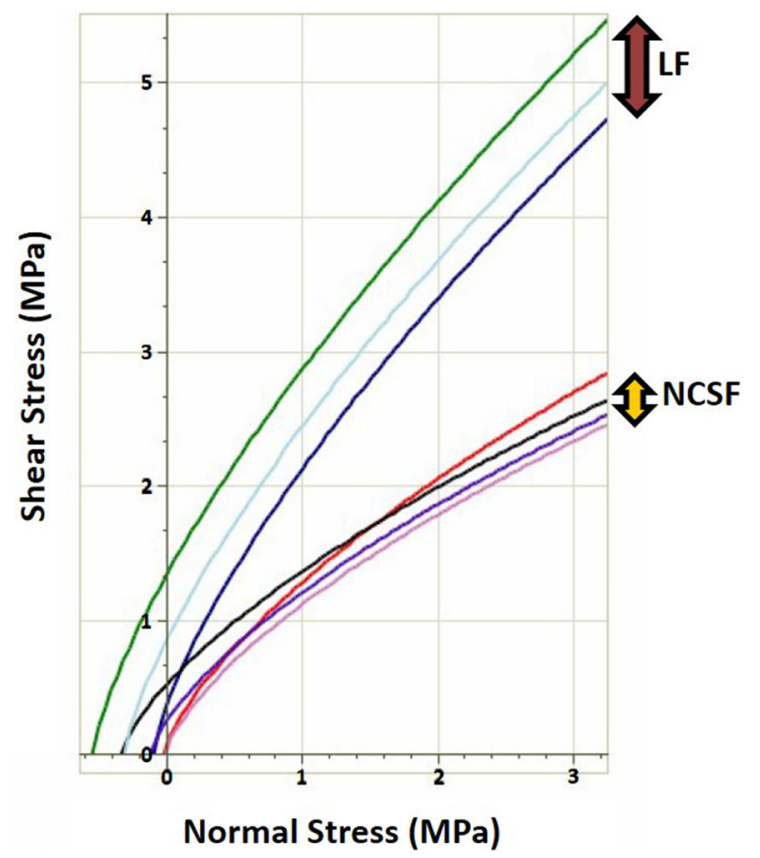

Fig. 7 Failure envelopes based on the Generalized HoekBrown Criterion

LF shows a cohesion of 1.0 MPa and a friction angle of $53^{\circ}$. The high friction angles of both units are attributed to the strongly curvilinear shape of the failure envelope at low confining pressures.

Oliveira (1990) states that rocks with a strength between 2 and $20 \mathrm{MPa}$ show Young's moduli of

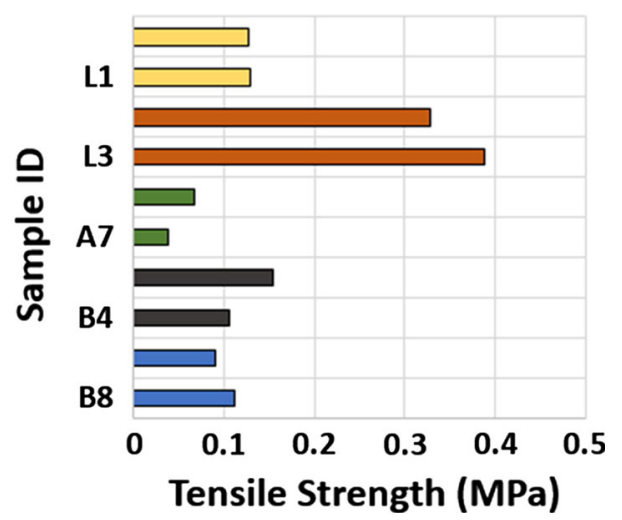

Fig. 8 Tensile strength of the NCSF and LF, two tests were conducted for each specimen

500-5000 MPa. The calculated values for Young's Modulus from the LF therefore appear appropriate. Considering the NCSF shows an average UCS of 1.5 $\mathrm{MPa}$ (air-dry), the calculated value of $257 \mathrm{MPa}$ is reasonable. Bell and Culshaw (1990) state higher values for Young's Modulus, but since their UCS values are already considerably higher, this does not conflict with the results from this project.

The calculated values of Poisson's ratio of approximately 0.1 for both units are lower than typical literature values for the SSG, of between 0.2 and 0.4 (Whitworth and Turner 1989) and around 0.23-0.25 according to Bell and Culshaw (1990). Grain movement at the interface due to the friability of the 
Table 4 Comparison of the engineering properties of the SSG in the TOQ to literature values around Nottinghamshire Engineering properties of the SSG in Nottinghamshire (Bell and Culshaw 1990; Yates 1992)

\begin{tabular}{|c|c|c|c|c|c|}
\hline & \multicolumn{3}{|l|}{ NCSF } & \multicolumn{2}{|l|}{$\mathrm{LF}$} \\
\hline & $\begin{array}{l}\text { Laboratory } \\
\text { testing results } \\
\text { average }( \pm \mathrm{SD})\end{array}$ & $\begin{array}{l}\text { Literature values } \\
\text { (Bell and Culshaw } \\
1990) \text { average } \\
( \pm \text { SD) }\end{array}$ & $\begin{array}{l}\text { Literature } \\
\text { values (Yates } \\
\text { 1992) average }\end{array}$ & $\begin{array}{l}\text { Laboratory } \\
\text { testing results } \\
\text { average }( \pm S D)\end{array}$ & $\begin{array}{l}\text { Literature values (Bell } \\
\text { and Culshaw 1990) } \\
\text { average }( \pm \text { SD) }\end{array}$ \\
\hline Dry density $\left(\mathrm{kg} / \mathrm{m}^{3}\right)$ & $1760( \pm 34)$ & $1830( \pm 50)$ & - & $2150( \pm 171)$ & $1940( \pm 40)$ \\
\hline Bulk density $\left(\mathrm{kg} / \mathrm{m}^{3}\right)$ & $1910( \pm 30)$ & - & - & $2250( \pm 157)$ & - \\
\hline $\begin{array}{l}\text { Saturated density }(\mathrm{kg} / \\
\left.\mathrm{m}^{3}\right)\end{array}$ & $2060( \pm 44)$ & $2090( \pm 40)$ & - & $2320( \pm 117)$ & $2130( \pm 70)$ \\
\hline Moisture content $(\%)^{\mathrm{a}}$ & $6.4( \pm 2.3)$ & - & - & $3.2( \pm 1.8)$ & - \\
\hline Porosity (\%) & $30.7( \pm 0.9)$ & $31.8( \pm 1.9)$ & - & $18.5( \pm 5.4)$ & $26.9( \pm 1.6)$ \\
\hline UCS oven-dry (MPa) & $0.516( \pm 0.669)$ & - & - & $26.0( \pm 12.3)$ & - \\
\hline UCS air-dry (MPa) & $1.53( \pm 0.822)$ & $11.8( \pm 4.1)$ & - & $15.4( \pm 11.0)$ & $14.7( \pm 1.8)$ \\
\hline UCS saturated (MPa) & $0.776( \pm 0.498)$ & $7.0( \pm 2.9)$ & 3.38 & $15.3( \pm 12.1)$ & $9.5( \pm 2.3)$ \\
\hline $\begin{array}{l}\text { Young's modulus } \\
\text { oven-dry* (MPa) }\end{array}$ & $155( \pm 143)$ & - & - & $4597( \pm 2433)$ & - \\
\hline $\begin{array}{l}\text { Young's modulus } \\
\text { airdry (MPa) }\end{array}$ & $257( \pm 133)$ & $6160( \pm 1980)$ & - & $3194( \pm 2400)$ & $7960( \pm 800)$ \\
\hline $\begin{array}{l}\text { Young's modulus } \\
\text { saturated* (MPa) }\end{array}$ & $258( \pm 164)$ & $3160( \pm 1390)$ & - & $3389( \pm 2993)$ & $4530( \pm 470)$ \\
\hline $\begin{array}{l}\text { Poisson's ratio airdry, } \\
\text { calculated }\end{array}$ & $0.119( \pm 0.055)$ & $0.23( \pm 0.05)$ & - & $0.0820(-)$ & $0.25( \pm 0.04)$ \\
\hline Tensile strength (MPa) & $0.095( \pm 0.036)$ & $0.74( \pm 0.45)$ & - & $0.243( \pm 0.116)$ & $0.85( \pm 0.32)$ \\
\hline $\begin{array}{l}\text { Slake durability (1st } \\
\text { cycle durability; } \\
\left.\mathrm{I}_{\mathrm{D} 1}\right) \text { ) }\end{array}$ & $4.6( \pm 6.4)$ & - & - & $59.3( \pm 34.8)$ & - \\
\hline $\begin{array}{l}\text { Slake Durability (2nd } \\
\text { cycle durability; } \\
\left.\mathrm{I}_{\mathrm{D} 2}\right) \text { ) }\end{array}$ & $2.1( \pm 2.9)$ & - & - & $51.5( \pm 33.6)$ & - \\
\hline $\begin{array}{l}\text { Peak strength } \\
\mathrm{c}^{\prime}(\mathrm{MPa}) / \varphi^{\prime}\left(^{\circ}\right) \text {; for } \sigma_{3} \\
\max .=1 \mathrm{MPa}\end{array}$ & $0.39 / 37.8$ & - & $0.7 / 49$ & $1.01 / 53.3$ & - \\
\hline $\begin{array}{l}\text { Peak strength } \\
\mathrm{c}^{\prime}(\mathrm{MPa}) / \varphi^{\prime}\left({ }^{\circ}\right) ; \text { for } \sigma_{3} \\
\max .=0.3 \mathrm{MPa}\end{array}$ & $0.29 / 45.6$ & - & $0.15 / 45$ & - & - \\
\hline
\end{tabular}

${ }^{\mathrm{a}}$ Moisture content of air-dry samples; does not correspond to natural moisture content

material can conceal the actual displacement and the lateral strain cannot be recorded adequately (Stenebraten and Fjaer 2009). Therefore, the calculated Poisson's ratio appears not to be representative and values from Bell and Culshaw (1990) are chosen instead for the stability analysis.

The low tensile values from this study can be attributed to the core orientation and anisotropy (Vallejo and Ferrer 2011). The achieved values are conservative and are suitable for the failure envelope's tensile cut-off.

The results from the laboratory testing are credible and in spite of possibly being influenced by endeffects and the mechanical impact from excavating and coring, the samples are deemed representative of the conditions on site. The exposure of the block samples to weathering possibly impacted the strength properties of the samples. Given the short exposure 


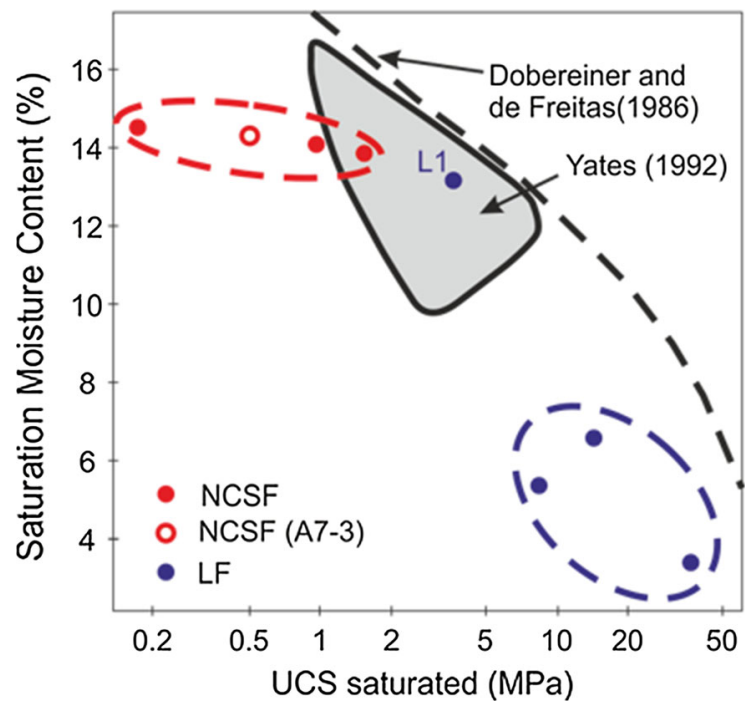

Fig. 9 Correlation of the saturation moisture content with the saturated UCS and comparison to literature values

time of the blocks of less than 8 months and the blocks being subcored to gain laboratory specimens, the influence of weathering is regarded to be negligible. Therefore the low strength of the rock determined from laboratory testing is an adequate representation of the formation's characteristics on site and is not attributed to poor sampling quality and extensive weathering.

\section{Geotechnical Characterization and Structural Assessment}

The process of transitioning from intact rock material to rock mass properties predominantly involves the analysis of discontinuities alongside weathering effects (Wyllie and Mah 2004).

A scanline survey is conducted, but due to access restrictions this survey is limited to one scanline along the face. The data are processed with the Rocscience software Dips 7.0 and the possibilities for planar failure, wedge failure, direct and flexural toppling are assessed. No samples containing discontinuities for shear box testing can be taken. This is a major limitation due to the dominant role of discontinuities in rock slope stability (Wyllie and Mah 2004). Parameters have to be derived from field observations and laboratory tests on intact rock. Barton and Choubey (1977) state that for rock slope design the asperity component can be neglected and the design is only based on the friction angle. Thus, the friction angle is determined using residual data from the triaxial tests by fitting a MC envelope.

Seven joints are identified along a $150 \mathrm{~m}$ long horizontal section. The angle of dip is more than $80^{\circ}$, they are highly persistent, rough to smooth and have no infill. The kinematic analysis indicates that failure occurs due to the rocks sliding on the base planes and no toppling is observed. The visual assessment of the discontinuities in the slope shows that the bedding is the most obvious feature (Fig. 10).

It is thinly to thickly bedded, horizontal, highly persistent, planar with smooth surfaces, very tight to partly open and no infilling can be seen. The residual parameters derived from the triaxial testing have been already stated in Table 3.

\subsection{Weathering Conditions}

The friability of the material and the easy disintegration into sand mean it is unlikely that a deterioration of strength properties over time is quantifiable before disintegration occurs. Due to time limitations an approach based on volume loss of blocks over time is chosen to quantify the material loss over the design life, resulting in weathering rates of $1 \mathrm{~m}$ per 10 years.

\subsection{Interpretation}

The upscaling to rock mass properties is difficult, with little information available about structural features. The author concludes that the bedding planes are the most dominant feature out of the discontinuities. The residual friction angle of the NCSF is $39^{\circ}$ and for the LF it is $43^{\circ}$, while no tensile strength and cohesion are assumed (Wyllie and Mah 2004). The obtained values for $\varphi b$ ' are very high for sedimentary rocks in comparison to those of de Vallejo and Ferrer (2011), who state $\varphi b$ ' to be between $25^{\circ}$ and $37^{\circ}$ for planar unweathered discontinuities in sedimentary rocks. This is due to the failure surface in the laboratory testing not being planar.

\section{Numerical Analysis-A Case Study}

The modelling of the rock slope is undertaken with two different Rocscience programmes, RS2 9.0 and 


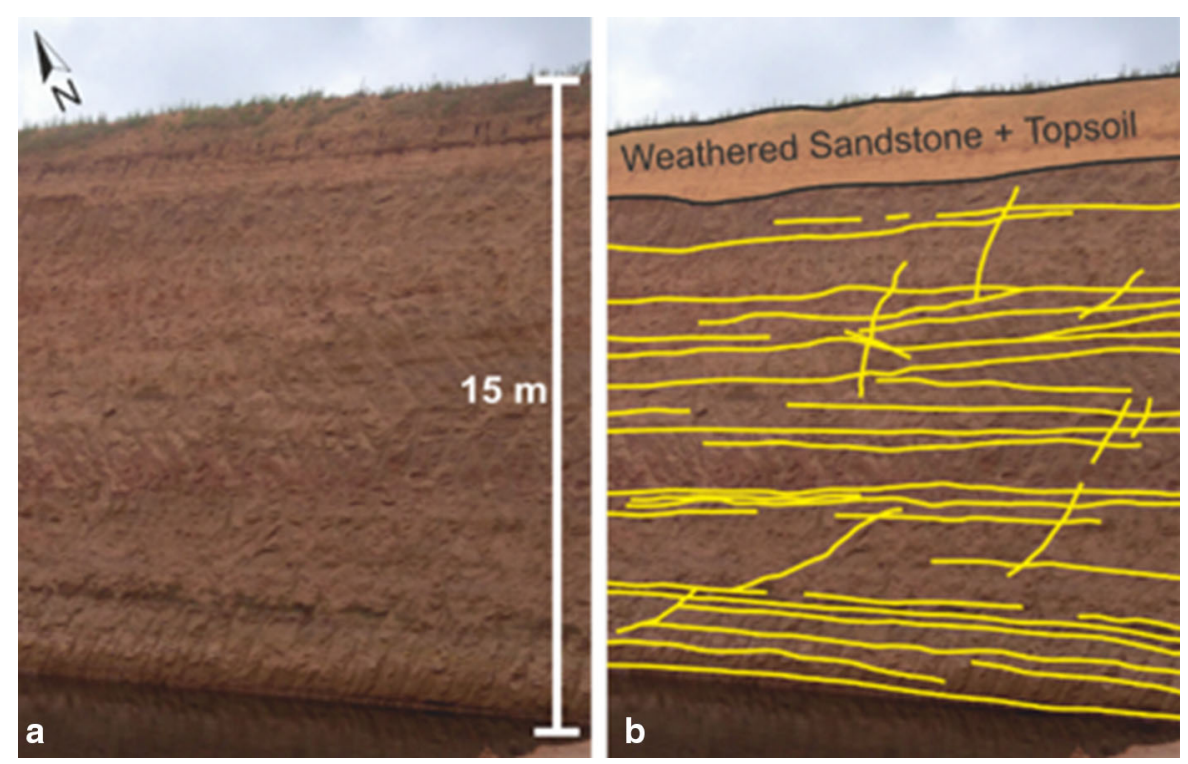

Fig. 10 Visual assessment of the slope highlighting the bedding planes and joints; a original picture; $\mathbf{b}$ edited showing structures

Slide 7.0 to compare the results. RS2 uses the Finite Element Method (FEM) and Slide is based on the Limit Equilibrium Method (LEM).

The LEM analyses a number of circular and noncircular slip surfaces based on assumptions about moment and force equilibrium. For this research, the Bishop Method (1955) is used for circular slip surfaces and the General Limit Equilibrium (GLE)/Morgenstern-Price (1965) and Janbu's Simplified Method (1957) are used for non-circular surfaces.

In the FEM (RS2) the Shear Strength Reduction Method (SSR) is used to determine the critical strength reduction factor (SRF). The SRF is a global factor of safety, similar to the FoS (Rocscience 2017). The SRF is also referred to as FoS in the following sections. In RS2 the stability is indicated by convergence. Nonconvergence is caused by excessive stress or displacement meaning the slope is unstable (Hammah et al. 2007).

The LEM and FEM require different input parameters (Table 5), with the FEM, allowing for a more material-specific analysis (Cheng and Lau 2014). One significant difference is that joints are modelled as zero-thickness elements in RS2 but must be modelled as thin material layers or with the anisotropic function in Slide.

The advantages of the FEM include that the critical failure surface is not pre-defined but based on the development of shear strain, without making any assumptions about the (inter)slice shear forces (Diederichs et al. 2007). The output includes information about the stress-strain response, which cannot be obtained from the LEM (Cheng and Lau 2014; Kanda and Stacey 2016). A limitation of the FEA is that the failure surface is not shown as a clearly defined thin layer, but as an area of maximum shear strain.

\subsection{Slope Stability Analysis}

\subsubsection{Slope Geometry and Parameters}

The friability of the material and the easy disintegration into sand mean it is unlikely that a deterioration of strength properties over time is quantifiable before disintegration occurs. Due to time limitations an approach based on volume loss of blocks over time is chosen to quantify the material loss over the design life, resulting in weathering rates of $1 \mathrm{~m}$ per 10 years.

The slope geometry is shown in Figure and a description of the strata boundaries and water table is stated in Sect. 2.2.3. A finite groundwater element analysis is used to determine the distribution of water in the slope. The description and comparisons from the stepwise building of the models can be seen in Table 5.

For design purposes, a FoS between 1.2 and 1.5 is recommended (Read and Stacey 2009), with the higher FoS of 1.5 being adopted for this study. The 
Table 5 Comparison of input parameters for FEM and LEM (modified after Kanda and Stacey 2016)

\begin{tabular}{clc}
\hline & FEM (RS2) & LEM (Slide) \\
\hline $\begin{array}{c}\text { Technical } \\
\text { factors }\end{array}$ & Number of meshing elements, type of elements, SSR & Number of slices, number of slip surfaces \\
$\begin{array}{c}\text { Material } \\
\text { factors }\end{array}$ & $\begin{array}{c}\text { Density, } \mathrm{c}^{\prime}, \varphi^{\prime}, \text { tensile strength, failure criterion, residual parameters, } \\
\text { dilation angle, stiffness characteristics (Young's Modulus, Poisson's } \\
\text { ratio) }\end{array}$ & $\begin{array}{c}\text { Density, saturated density, } \mathrm{c}^{\prime}, \varphi^{\prime}, \text { tensile } \\
\text { strength, failure criterion }\end{array}$ \\
Joints & $\begin{array}{c}\text { Normal and shear stiffness, dilation angle } \\
\text { Modelled as material layers, using the } \\
\text { material factors shown in the column above }\end{array}$ \\
\hline
\end{tabular}

external boundary is determined according to the requirements set out by Lorig and Varona (2004). A uniform mesh with 6-noded triangles and approximately 3000 elements is chosen, based on research regarding minimum requirements by Kanda and Stacey (2016).

Elastio-plastic behaviour was assumed for the material for both the FEM and LEM (Hammah et al. 2005). The material properties derived from the laboratory testing are used, except for Poisson's ratio and the permeability (Tables $1,5,6)$.

The discontinuities in RS2 are modelled as zerothickness elements, with open ends at the boundary contact (Hammah et al. 2009). In Slide, the bedding planes are modelled as $0.1 \mathrm{~m}$ thick material layers and are assigned the joint properties (Fig. 10 and Table 5). Since the modelling of thin layers is impractical for closely spaced discontinuities, the material is modelled as an anisotropic medium at later stages. It should be also stated that the residual properties are shown in Table 6 where the residual cohesion assumed to be 0 . The residual input parameters are derived from the post-peak behaviour of the triaxial test samples and are also used for the modelling of the weak layers/discontinuities.

Table 6 Geotechnical parameters used in numerical analyses

\begin{tabular}{|c|c|c|c|c|}
\hline Input parameters & NCSF & $\mathrm{LF}$ & Weak layers/joints in NCSF & Joints LF \\
\hline Initial element loading & Field stress and body force & Field stress and body force & $\begin{array}{l}\text { Field stress and body force/ } \\
\text { N/A }\end{array}$ & N/A \\
\hline Unit weight $\left(\mathrm{kN} / \mathrm{m}^{3}\right)$ & 19.1 & 22.5 & 19.1 & N/A \\
\hline Saturated unit weight $\left(\mathrm{kN} / \mathrm{m}^{3}\right)$ & 20.6 & 23.2 & 20.6 & 23.2 \\
\hline Strength criterion & $\mathrm{MC} / \mathrm{HB}$ & $\mathrm{MC} / \mathrm{HB}$ & $\mathrm{MC}$ & $\mathrm{MC}$ \\
\hline Tensile strength (MPa) & 0.095 & 0.243 & 0 & 0 \\
\hline Friction angle $\left({ }^{\circ}\right)$ & 45.6 & 54.8 & 38.7 & 42.9 \\
\hline Cohesion (MPa) & 0.29 & 0.88 & 0 & 0 \\
\hline Young's modulus (MPa) & 257 & 3194 & 78 & N/A \\
\hline Poisson's ratio & 0.23 & 0.25 & 0.23 & N/A \\
\hline Residual tensile strength (MPa) & 0 & 0 & 0 & 0 \\
\hline Residual friction angle $\left(^{\circ}\right)$ & 38.7 & 42.9 & 38.7 & 42.9 \\
\hline Residual cohesion $(\mathrm{kPa})$ & 0 & 0 & 0 & 0 \\
\hline Dilation angle $\left(^{\circ}\right)$ & 0 & 0 & 0 & 0 \\
\hline Joint normal stiffness $(\mathrm{MPa} / \mathrm{m})$ & N/A & N/A & 78.3 & 919.5 \\
\hline Joint shear stiffness $(\mathrm{MPa} / \mathrm{m})$ & N/A & N/A & 7.8 & 92 \\
\hline
\end{tabular}


An adaptive modelling approach was chosen, where the model is gradually built up and simple models are used to analyse the influence of specific parameters. These are incorporated into a more complex model in the final step (Starfield and Cundall 1988). The influence of several key variables on the stability is assessed:

- Spacing of bedding

- Inclination of joints

- Material loss from weathering

- Permeability

Material strength based on the standard deviation determined from the laboratory tests (Sect. 3.5). Young's Modulus, Poisson's ratio and the dilation angle are kept constant based on the work by Hammah et al. (2005), who demonstrate that these parameters have no significant impact on the slope stability.

\subsubsection{Numerical Results}

A total number of 26 models is analysed in RS2 and compared to the equivalent models in Slide. The description and comparisons from the stepwise building of the models can be seen in Table 7 and Fig. 11. M1 and M2 give similar results for both programmes and analysis methods. M3 shows that for non-circular failure the results are almost identical to RS2, but a big difference to the circular failure mode is evident.

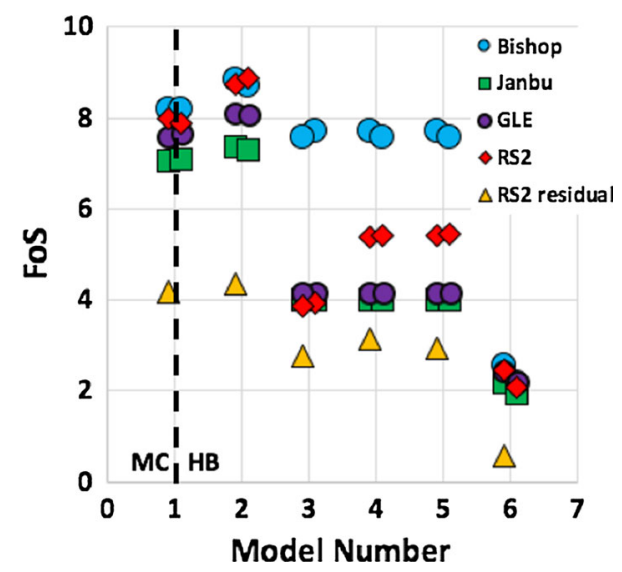

Fig. 11 Comparison of the FoS for the models M1 to M6 based on different methods of analysis; for each model: left: FoS determined by equivalent MC parameters; right: FoS determined by $\mathrm{HB}$ parameters
When comparing the weak layer layout (M3) to discrete zero-thickness joints in RS2 (M5), differences in the FoS are evident. The two methods are compared in detail in Fig. 12. The most significant feature is the different distribution of shear strain. When modelling zero-thickness elements (see Fig. 12, M5, right side), a zone of increased shear strain in the intact rock is observed, whereas in the weak layer model (see Fig. 12, M3, left side) the increased shear strain is restricted to the weak layers. The displacement contours in the RS2 models indicate movement along several discontinuities in comparison to one distinct failure surface determined by the LEM (Janbu/GLE). Figure 12 also shows that the displacement is restricted to the NCSF and the LF is not affected.

The following results are gained from changing the parameters in M4 and M5 to assess the impact on the FoS. In Fig. 13a, it is shown that an anticlockwise rotation (dip direction: $\mathrm{SW}$ ) promotes instability more than a clockwise rotation (dip direction: NE). Variable spacing of the bedding planes has little impact on the FoS (Fig. 13b). Only minor differences are evident when applying discontinuities in the LF in addition to the NCSF. The relation between material loss from weathering and the FoS is shown in Fig. 13c. The sensitivity plot (Fig. 13d) shows that the cohesion within the range determined from the laboratory testing for the NCSF has the biggest influence on the stability.

Different permeability combinations are trialled and a minor influence on the FoS is detected (Table 8).

The above results are incorporated into the most realistic model of the slope (M100). Bedding planes are modelled as weak layers in the NCSF with an ACW inclination of $10^{\circ}$, a thickness of $0.1 \mathrm{~m}$ and a spacing of $1 \mathrm{~m}$. The estimated material loss of 3 metres on either side (Sect. 4.1) is used for the long-term stability analysis. Application of this model results in a FoS of 1.68 in RS2 compared to 1.81 for both the Janbu and the GLE Method in Slide. The displacement contours are shown in Fig. 14.

The shear strain and total displacement are determined along a vertical section at the crest of the slope (Fig. 15) to see the distribution.

In Table 9 the critical strength parameters leading to failure are displayed. 
Table 7 Description of the input parameters for the models in RS2 and Slide

\begin{tabular}{ll}
\hline Model & Description \\
\hline M1 & Geology, no water \\
M2 & Geology, water \\
M3 & Geology, water, NCSF, LF: planes of weakness: $1 \mathrm{~m}$ spacing, $0.1 \mathrm{~m}$ thick \\
M4 & RS2: Geology, water, joints in NCSF with $1 \mathrm{~m}$ spacing \\
& Slide: Geology, water, planes of weakness: $1 \mathrm{~m}$ spacing, $0.1 \mathrm{~m}$ thick \\
M5 & RS2: Geology, water, joints in NCSF, LF with $1 \mathrm{~m}$ spacing \\
& Slide: Geology, water, planes of weakness: $1 \mathrm{~m}$ spacing, $0.1 \mathrm{~m}$ thick \\
M6 & Geology, water, NCSF, LF: GSI 45 [Flysch Classification; Marinos and Hoek $(2001)]$ applied to strength parameters \\
M100 & Final model: Geology, ponded water + water table, weak layers in NCSF, $1 \mathrm{~m}$ spacing, $0.1 \mathrm{~m}$ thick, inclination of $10^{\circ}, 3 \mathrm{~m}$ \\
& material loss due to weathering \\
\hline
\end{tabular}

\subsubsection{Numerical Results Discussion}

When comparing Models M1 to M6 (Fig. 11), in general, a trend of decreasing FoS is evident once anisotropy by weak layers and joints is added to the model. The equivalent MC and $\mathrm{HB}$ parameters give almost identical results, with an absolute deviation of less than 0.2, showing that both methods are appropriate.

For M1 and M2, the results from RS2 and the Bishop Method are almost identical, suggesting that a circular failure mechanism is applicable for these isotropic models. The Bishop Method overestimates the FoS, once discrete joints and weak layers are added. Azami et al. (2012) support the observation that the presence and orientation of the weakness planes impacts on the shape of the failure surface. Modelling the planes of weakness as $0.1 \mathrm{~m}$ thick layers (M3) in RS2 and Slide gives almost identical results to the noncircular analysis. When comparing the $0.1 \mathrm{~m}$ thick layers (M3) to the zero-thickness elements (M4), a significantly higher FoS is observed for the zerothickness elements in RS2, showing that thicker weak layers generally promote instability. For this research project, it needs to be discussed what the more valid approach is. The layers/joints have to represent areas of weakness, including bedding planes, but also weaker beds with poor cementation and very little to no cohesion, which have a considerable thickness. The different approaches for modelling weak layers and discontinuities result in a different shear strength distribution. When zero-thickness elements are used, a zone of increased shear strain in the intact rock is evident, whereas in the weak layer model the increased shear strain is restricted to the weak layers. This shows that the failure of model M4/M5 (zero thickness elements as joints) cannot solely be generated by the discontinuities. A combination with failure of intact rock is needed, whereas in M3 failure occurs exclusively along the weak layers.

When applying residual properties, the FoS is consistently lower than the elastic-perfectly plastic analysis. In the SSR Method, both the intact and residual properties are reduced (Rocscience 2017), which results in the low FoS which is not applicable to the slope and not comparable to the LEM. The use of the GSI to describe the rock mass (M6), displays a significantly lower FoS than any of the other models. This shows that it is very difficult and unsuitable in this study to analyse the rock mass as a continuum without discrete discontinuities/weak layers, especially if the bedding is a prominent feature controlling stability. An anisotropic analysis shows a flat failure surface and the FoS is low in comparison to the jointed models. The absence of intact material in the horizontal direction leads to an underestimation of the rock mass strength, because shear failure does not have to propagate through intact material in between discontinuities. The anisotropic model is unsuitable and shows that the representation without weak layers is not adequate.

The assessment of key parameters influencing the slope stability shows that an inclination of the planes, which is locally possible because of cross bedding, has adverse effects on the stability and needs to be accounted for (Fig. 13a). The disintegration of the 


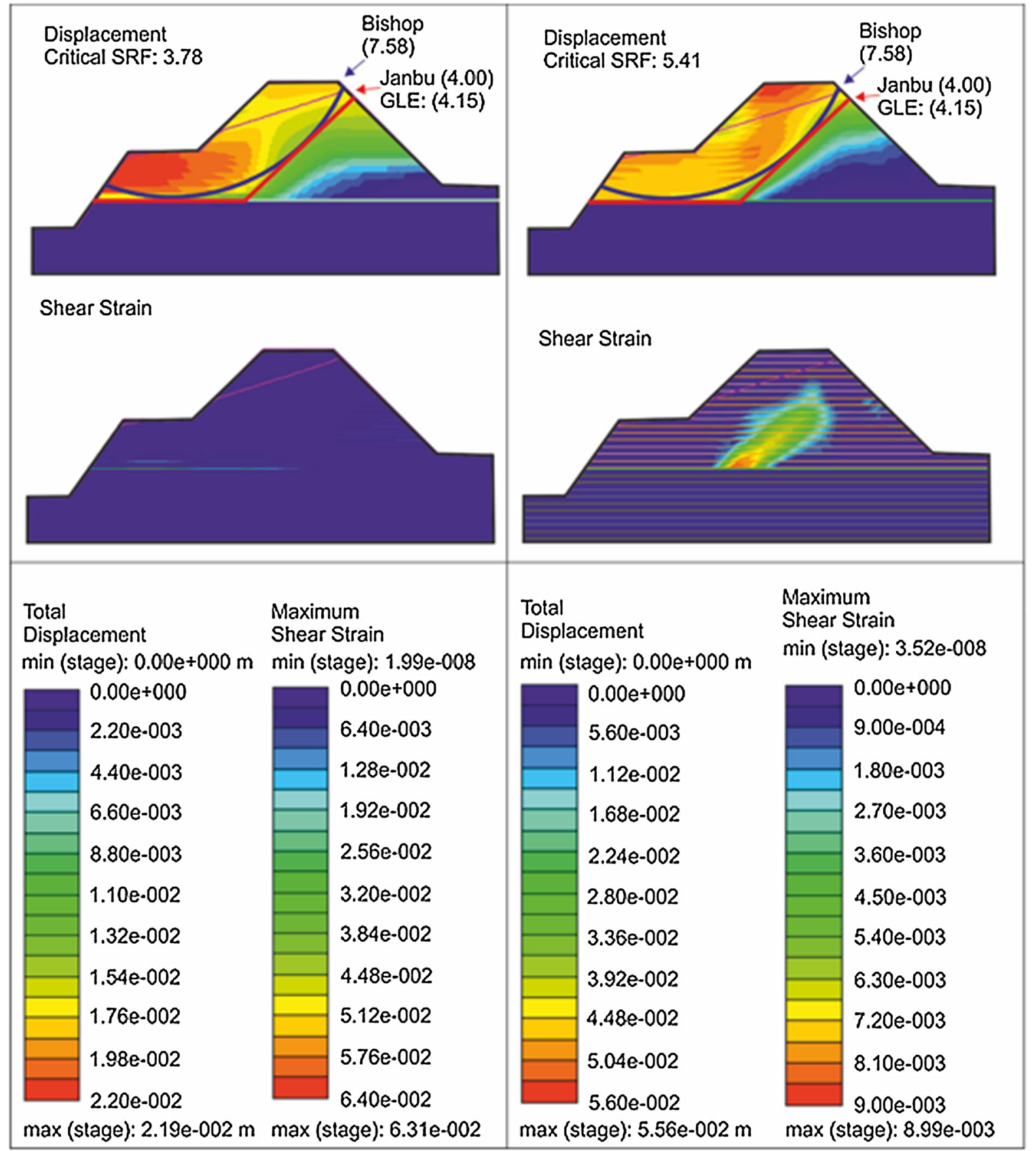

Fig. 12 Comparison of M3 (planes of weakness $0.1 \mathrm{~m}$ thick; on the left) and M5 (joints as zero-thickness elements; on the right); showing the failure surfaces from RS2 and Slide and

material due to weathering is another major influence, which considerably lowers the FoS (Fig. 13c). Although permeability does not alter the results significantly (Table 8 ) it holds potential for failure displacement contours (top) and the deformation of the boundaries (middle) and shear strain (bottom) modelled with RS2

by internal piping, caused by the hydraulic gradient ultimately leading to the erosion of the material (Read and Stacey 2009). This is particularly the case along the bedding and weak layers, which act as preferred 
Fig. 13 a Influence of the inclination of the bedding on the FoS for intact and residual parameters for M5 (Inclination from the horizontal, positive: anticlockwise rotation; negative: clockwise rotation); $\mathbf{b}$ influence of the spacing of the bedding planes on the FoS for joints in the NCSF and joints in both the NCSF and LF for M4 and M5; $\mathbf{c}$ influence of weathering and material loss on the FoS for M4;

d Sensitivity of the NCSF regarding changes in cohesion, friction angle and unit weight, based on the standard deviation from the laboratory testing (based on M2)
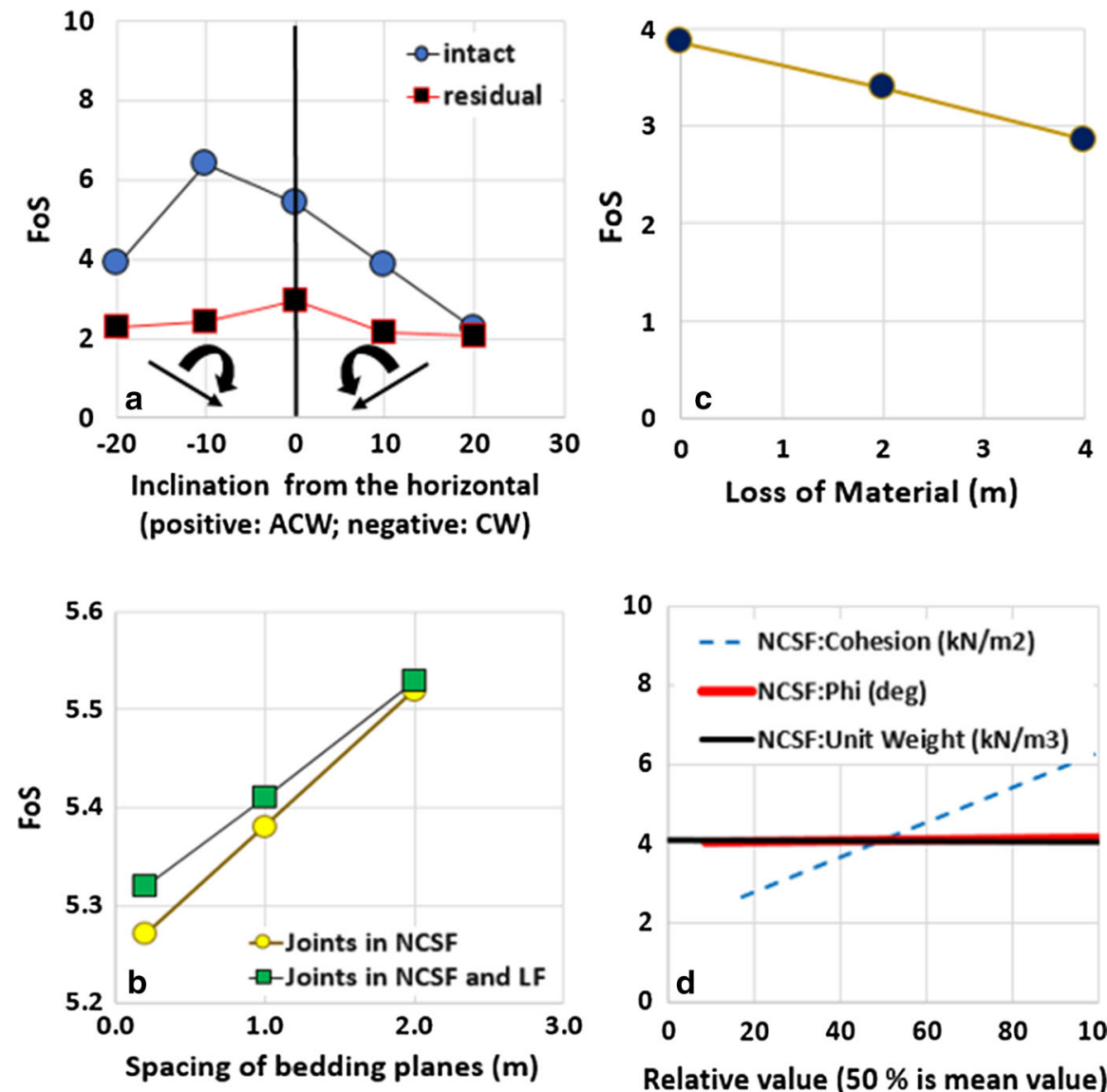

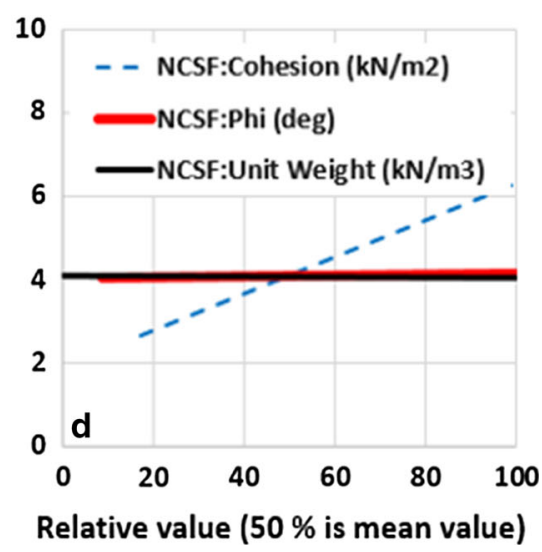

Table 8 Influence of the different permeability combinations on the FoS for M3

\begin{tabular}{lll}
\hline Unit & Permeability $(\mathrm{m} / \mathrm{s})$ & FoS \\
\hline NCSF, LF, weak layers & $1.00 \mathrm{E}-03$ & 3.88 \\
NCSF, LF, weak layers & $1.00 \mathrm{E}-07$ & 3.87 \\
NCSF, LF, weak layers & $1.00 \mathrm{E}-20$ & 3.85 \\
NCSF & $3.80 \mathrm{E}-07$ & 4.07 \\
LF & $1.90 \mathrm{E}-07$ & 4.07 \\
Weak layers & $2.00 \mathrm{E}-03$ & 4.07 \\
\hline
\end{tabular}

flow paths where internal erosion occurs (Richards and Reddy 2007). Besides, the pore pressure changes the effective stress in the slope and exerts uplift pressures (de Vallejo and Ferrer 2011). The use of a liner for the lagoons is recommended to prevent this.

The final model (M100) containing all this information is stable with a FoS of 1.68 (RS2) and 1.81 (Slide). The comparison between the LEM and the
FEM shows that the FoS are very similar for both, but differences regarding the failure mechanism are observed. Both programmes indicate a non-circular failure mechanism, with the failure surface propagating along weak layers without involving the intact rock. In RS2 shear strain develops along the bedding planes, with no increase in shear strain being observed in the intact rock (Fig. 15). This leads to the planes of weakness being successively displaced, with insignificant displacement shown in the intact rock (Fig. 15). The failure surface indicated by RS2 shows a complexity, which cannot be represented by Slide. In contrast to RS2, Slide indicates that failure occurs along one discrete weak layer. Slide is not capable of indicating the stepwise displacement, without the involvement of intact rock. Both programmes show no involvement of the LF in the failure mechanism, owing to its higher strength.

The water behind the slope is one important driving force, which allows the displacement along almost horizontal layers. To reach the CSRF, a reduction of 
Total

Displacement

$\min$ (stage): $0.00 \mathrm{e}+000 \mathrm{~m}$

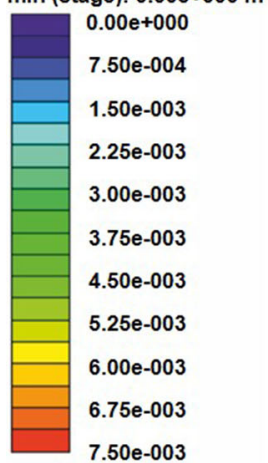

$\max$ (stage): $7.49 \mathrm{e}-003 \mathrm{~m}$

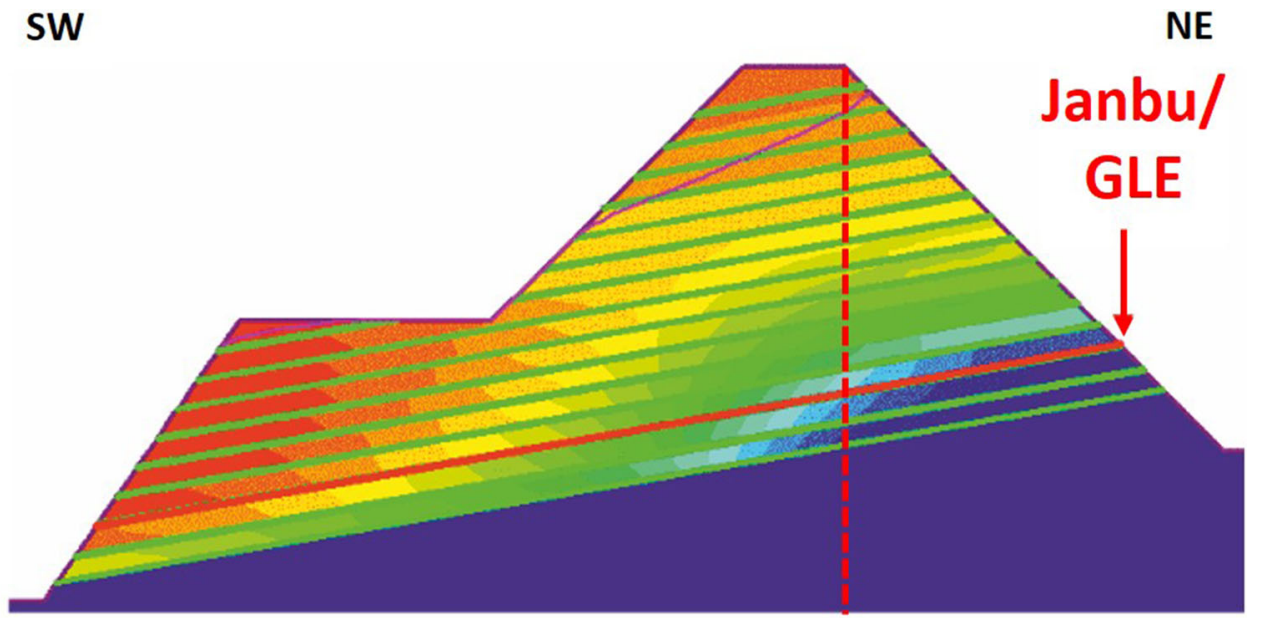

Fig. 14 Display of failure surface for the LEM and total displacement contours from the FEA for M100 (CSRF: 1.68)

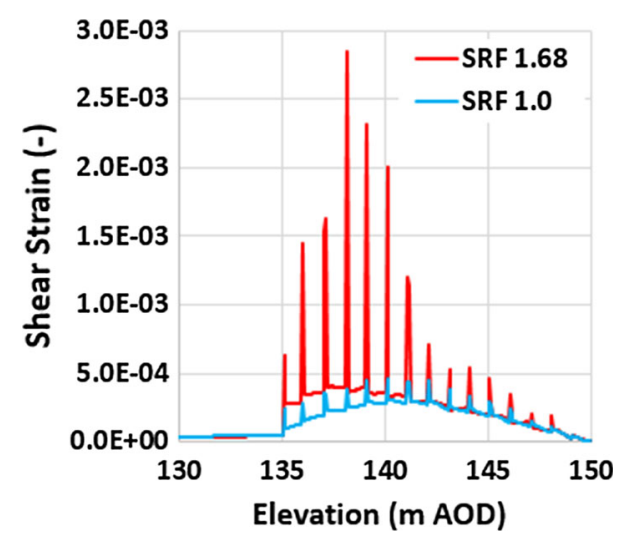

Fig. 15 Plot of the shear strain values for SRF: 1 and CSRF: 1.68 for M100 along the query line from Fig. 14

Table 9 Strength parameters leading to failure at the CSRF: 1.68 for M100

\begin{tabular}{llll}
\hline Material & NCSF & LF & Weak layers \\
\hline Cohesion $(\mathrm{kPa})$ & 173 & 595 & 0 \\
Angle of friction $\left(^{\circ}\right)$ & 31.3 & 38.9 & 25.5 \\
\hline
\end{tabular}

the strength parameters by a factor of 1.68 is necessary to achieve non-convergence of the FEM analysis, representing failure of the slope. For weak layers, this means the friction angle is reduced to $25.5^{\circ}$ (Table 9), which is unrealistic for sands (Waltham 2009). Hence the cohesion-less layers are stable in the long-term and
Fig. 16 Geotechnical model derived from the laboratory results, structural features and the slope stability analysis; green box: indicating location in the quarry

no instability is expected. Given the FoS/CSRF is higher than the threshold of 1.5, the slope is stable. Even though the factor 1.68 in the SSR method is called the critical strength reduction factor, the FoS/ CRSF is higher than 1.5 and therefore the slope is stable. The term "critical" can be misleading and only describes the non-convergence of the model but does not describe the condition of the slope.

The comparison of Slide and RS2 shows that the SSR Method is applicable for modelling the response of the slope. Other authors have previously verified the applicability of the SSR to jointed rock masses (Hammah et al. 2007; Diederichs et al. 2007). In comparison to the solely structurally controlled mechanism, which was found in this project, Hammah et al. (2007) describe a combination of the failure of intact rock and movement along discontinuities. The geometry of the investigated examples by Hammah et al. (2007) and Diederichs et al. (2007) are "typical slopes", with intact rock behind the crest extending to the external boundary. The layout studied in this dissertation is more similar to a dam, which makes the sliding along discontinuities without the involvement of intact rock possible. It is recognized that the comparison to a dam is far-fetched, but it presents the idea that shearing occurs along planar (sub)horizontal 


\section{Summary of Findings- TOQ}

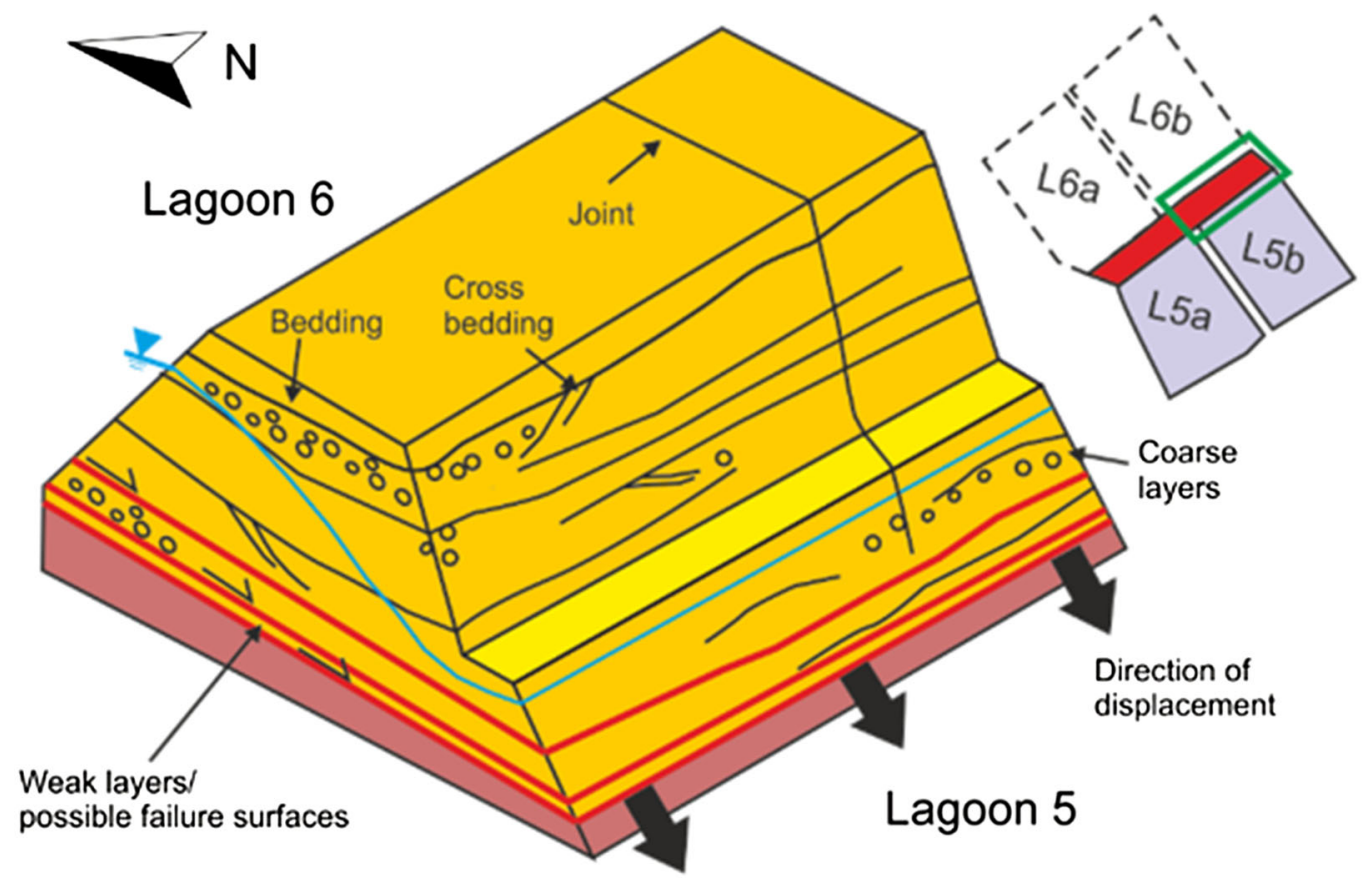

\begin{tabular}{|c|c|c|}
\hline & NCSF & LF \\
\hline Description & $\begin{array}{l}\text { Extremely to very weak, thinly to very } \\
\text { thickly bedded, reddish brown, medium } \\
\text { grained SANDSTONE (NCSF). } \\
\text { Contains mudstone clasts and sandy } \\
\text { and pebbly interlayers and lenses. }\end{array}$ & $\begin{array}{l}\text { Very weak to medium strong, thinly } \\
\text { to thickly bedded, dark red brown, } \\
\text { fine to medium grained } \\
\text { SANDSTONE (LF). Contains } \\
\text { mudstone clasts. }\end{array}$ \\
\hline Discontinuities & $\begin{array}{l}\text { Bedding: thinly to very thickly bedded, } \\
\text { subhorizontal/horizontal, very highly } \\
\text { persistent, smooth, planar, very tight to } \\
\text { partly open, clean; } \\
\text { Joints: very widely spaced, dipping } \\
\sim 80^{\circ} \text {, highly persistant, smooth to rough. }\end{array}$ & $\begin{array}{l}\text { Bedding: very thinly to very thickly } \\
\text { bedded, subhorizontal/horizontal, } \\
\text { very highly persistent } \\
\text { Limited information in the TOQ, } \\
\text { because it does not crop out. More } \\
\text { information about quality required. }\end{array}$ \\
\hline Weathering & $\begin{array}{l}\text { Very low durability; disintegration in } \\
\text { short periods of time (less than } 1 \text { year). }\end{array}$ & Very low to medium high durability. \\
\hline $\begin{array}{l}\text { Average value: } \\
\text { Dry density } \\
\text { UCS air-dry } \\
\text { UCS sat. } \\
\text { Young's M. } \\
\text { Cohesion } \\
\text { Angle of friction } \\
\text { Tensile strength }\end{array}$ & $\begin{array}{l}1760 \mathrm{~kg} / \mathrm{m} 3 \\
1.5 \mathrm{MPa} \\
0.8 \mathrm{MPa} \\
257 \mathrm{MPa} \\
0.29 \mathrm{MPa} \\
46^{\circ} \\
0.1 \mathrm{MPa}\end{array}$ & $\begin{array}{l}2150 \mathrm{~kg} / \mathrm{m} 3 \\
15.4 \mathrm{MPa} \\
15.3 \mathrm{MPa} \\
3194 \mathrm{MPa} \\
1.0 \mathrm{MPa} \\
54^{\circ} \\
0.2 \mathrm{MPa}\end{array}$ \\
\hline $\begin{array}{l}\text { FoS Slope } \\
\text { Mode of failure }\end{array}$ & \multicolumn{2}{|c|}{$\begin{array}{l}1.68 \text { (RS2) } \\
\text { Planar sliding along weak layers/ bedding planes in NCSF; } \\
\text { LF not affected. }\end{array}$} \\
\hline
\end{tabular}


discontinuities, without involving intact rock, as a credible failure mechanism and one which has led to dam failure in the past (Fell et al. 2014).

The examination of the slope in the TOQ shows that the FEM and LEM complement each other and that both methods shall be used to gain the most reasonable and realistic result. One of the problems in RS2 is that it is tempting for the user to represent weak layers as zero-thickness elements instead of material layers. Displaying closely spaced discontinuities as joint sets in RS2 is a lot simpler than modelling multiple material boundaries, but significantly overestimates the FoS in studies involving weak rocks.

\section{Concluding Remarks}

In summary, the analysis shows that the description of the NCSF as an extremely to very weak rock and the $\mathrm{LF}$ as a very weak to medium strong rock is applicable. The geotechnical model for the site including the most important findings from this research is shown in Fig. 16.

The weaker layers and the weathering characteristics are shown to significantly impact the design. The (spatial) variability of the SSG is evident and highlights the need for a suitable SI for each project on an individual basis. The use of literature values in design can, and in the case of this project would have, led to a significant over-estimation of the strength and to unsafe design. The preliminary layout of the slope was shown to be safe and is recommendable once issues regarding piping failure have been addressed.

This project shows how limited the information about weak rock is available and even less is known about extremely weak rocks. Sampling and testing difficulties in weak rock are well described in literature, but little advances are made on how these can be prevented. In-situ tests are a more adequate way of characterizing weak rock masses (Oliveira 1990) and shall be adopted for future investigations.

The results from the laboratory testing do not represent the natural moisture content and given the possible deterioration of the strength with increasing saturation, the use of air-dry samples may be a slight overestimation. The time-consuming preparation of the specimen due to core loss and limited availability of samples allowed for only a small number of tests to be conducted. A significantly higher number of samples is necessary to assess the strength in a saturated state because of the possibility of disintegration. Difficulties were encountered when determining Young's Modulus and Poisson's ratio. The friability of the material prevented the acquisition of representative results for Poisson's ratio. This can be counteracted by determining the volumetric strain using a circumferential extensometer (Stenebraten and Fjaer 2009).

One major limitation in this research work is the characterisation of discontinuities mainly based on laboratory parameters. Additional boreholes along the slope are recommended to discount the possibility of clay infill, especially in the LF and at the boundary to the NCSF. In case infill is encountered, it is recommended to repeat the slope stability analysis. A significantly lower FoS must be expected (Wyllie and Mah 2004).

All the limitations stated above need to be addressed and overcome to gain a better understanding of extremely weak rock and the SSG in particular. Further research is necessary, investigating the disturbance of drilling and sampling to the rock material which can lead to an underestimation of the strength causing uneconomic and overconservative design.

In particular, further research is required to assess the weathering characteristics for a time scale applicable to engineering projects (Paraskevopoulou et al. 2017). The depth and variability of weathering over geological times has been studied in depth (Tye et al. 2011) but no information regarding shorter periods is available. Therefore, the Slake Durability test is the most used method of quantifying the weathering characteristics, but as stated above, is often not applicable. Nickmann et al. (2006) propose a new approach specifically for weak rock. It is based on wetting and drying cycles while the sample is stationary, and the UCS, porosity, grain size and swelling characteristics are included in the evaluation. Since no mechanical impacts impair the sample and the high porosity of the SSG is considered, this may be a more adequate representation and worth considering for future research. The TOQ is an ideal site to observe and quantify the weathering impact: observing and measuring the retrogression of the face due to a loss of material is a simple way to quantify the weathering. Representative results can potentially be obtained in relatively short periods considering the weakness and poor cementation of the rock. 
Acknowledgements The authors would like to acknowledge the assistance of Greenfield Associates for providing data and assisting during field work.

Open Access This article is distributed under the terms of the Creative Commons Attribution 4.0 International License (http:// creativecommons.org/licenses/by/4.0/), which permits unrestricted use, distribution, and reproduction in any medium, provided you give appropriate credit to the original author(s) and the source, provide a link to the Creative Commons license, and indicate if changes were made.

\section{References}

Allen DJ, Brewerton LJ, Coleby BR, Gibbs BR, Lewis MA, MacDonald AM, Wagstaff SJ, Williams AT (1997) The physical properties of major aquifers in England and Wales. British Geological Survey, Keyworth

Ambrose K, Hough E, Smith NJP, Warrington G (2014) Lithostratigraphy of the Sherwood Sandstone Group of England, Wales and south-west Scotland. British Geological Survey, Keyworth

Azami A, Yacoub T, Curran J (2012) Effects of strength anisotropy on the stability of slopes. In: 65th Canadian geotechnical conference, CGS Geo-Manitoba, 30 Sept 2012-3 Oct 2012, Winnepeg. www.rocscience.com. Accessed 23 Aug 2017

Barton N, Choubey V (1977) The shear strength of rock joints in theory and practice. Rock Mech 10:1-54

Bell FG, Culshaw MG (1990) A survey of the geotechnical properties of some relatively weak Triassic sandstones. In: Cripps JC, Coulthard JM, Culshaw MG, Forster A, Hencher SR, Moon CF (eds) The engineering geology of weak rock. Proceedings of the 26th annual conference of the engineering group of the geological society, 9-13 Sept 1990, Leeds. Balkema, Rotterdam, pp 139-148

Bell FG, Culshaw MG, Forster A, Nathanail CP (2009) The engineering geology of the Nottingham area, UK. In: Culshaw MG, Reeves HJ, Jefferson I, Spink TW (eds) Engineering geology for tomorrow's cities. Geological Society, London, pp 1-24

Bieniawski ZT, Hawkes I (1978) Suggested methods for determining tensile strength of rock materials. Int J Rock Mech Min Sci \& Geomech Abstr 15(3):99-103

Bieniawski ZT, Franklin JA, Bernede MJ, Duffaut P, Rummel F, Horibe T, Broch E, Rodrigues E, van Heerden WL, Vogler UW, Hansagi I, Szlavin J, Bradi BT, Deere DU, Hawkes I, Milovanovic D (1979) Suggested methods for determining the uniaxial compressive strength and deformability of rock materials. Int J Rock Mech Min 16(2):135-140

British Geological Survey (BGS) (2017a) Engineering geological map viewer. http://www.bgs.ac.uk/. Accessed 22 June 2017

British Geological Survey (BGS) (2017b) The BGS Lexicon of named rock units. http://www.bgs.ac.uk/. Accessed 9 June 2017

British Standards Institution (2003) Geotechnical investigation and testing - identification and classification of rock-part
1: identification and description. British Standards Institution, London

British Standards Institution (2015) BS 5930: 2015 code of practice for ground investigations. British Standards Institution, London

Cheng YM, Lau CK (2014) Slope stability analysis and stabilization-new methods and insight, 2nd edn. CRC Press, London

de Vallejo LIG, Ferrer M (2011) Geological engineering. CRC Press, London

Dhakal GP, Kodama J, Yoneda T, Neaupane KM, Goto T (2004) Durability characteristics of some assorted rocks. J Cold Reg Eng 18(3):110-122

Diederichs MS, Lato M, Hammah R, Quinn P (2007) Shear strength reduction approach for slope stability analyses. In: 1st Canada-U.S. rock mechanics symposium, 27-31 May, Vancouver. www.onepetro.org. Accessed 20 Aug 2017

Dobereiner L, de Freitas MH (1986) Geotechnical properties of weak sandstones. Géotechnique 36(1):79-94

Fell R, MacGregor P, Stapledon D, Bell G, Foster M (2014) Geotechnical engineering of dams, 2nd edn. CRC Press, London

Franklin JA (1983) Suggested methods for determining the strength of rock materials in triaxial compression. Int $\mathrm{J}$ Rock Mech Min 20(6):285-290

Franklin JA, Vogler UW, Szlavin J, Edmond JM, Bieniawski ZT (1979) suggested methods for determining water content, porosity, density, absorption and related properties and swelling and slake-durability index properties. Int J Rock Mech Min 16(2):141-156

Freitas MH (1990) Weak arenaceous materials. In: Cripps JC, Coulthard JM, Culshaw MG, Forster A, Hencher SR, Moon $\mathrm{CF}$ (eds) The engineering geology of weak rock. Proceedings of the 26th annual conference of the engineering group of the geological society, 9-13 Sept 1990, Leeds. Balkema, Rotterdam, pp 115-123

Greenfield Associates (2013) Ground investigation and factual geotechnical report two oaks farm, Kirkby-in-Ashfield. (Unpublished)

Hammah RE, Yacoub TE, Corkum B, Curran JH (2005) A comparison of finite element slope stability analysis with conventional limit-equilibrium investigation. In: Proceedings of the 58th Canadian geotechnical and 6th joint IAHCNC and CGS groundwater speciality conferences, Sept 2005, Saskatoon. www.rocscience.com. Accessed 24 Aug 2017

Hammah RE, Yacoub T, Corkum B, Wibowo F, Curran JH (2007) Analysis of blocky rock slopes with finite element shear strength reduction analysis. In: Proceedings of the $1 \mathrm{st}$ Canada-US rock mechanics symposium, 27-31 May 2007, Vancouver. www.rocscience.com. Accessed 12 Aug 2017

Hammah RE, Yacoub T, Curran JH (2009) Variation of failure mechanisms of slopes in jointed rock masses with changing scale. In: Proceedings of the CIM 2009 conference, May 2009, Toronto. www.rocscience.com. Accessed 12 Aug 2017

Hoek E, Carranza-Torres C, Corkum B (2002) Hoek-Brown failure criterion-2002 edition. In: Proceedings of NARMS-TAC conference, Toronto, 2002. www. rocscience.com. Accessed 25 July 2017 
ISRM (1981) Basic geotechnical description of rock masses. Int J Rock Mech Min 18:85-110

ISRM (2007) The complete ISRM suggested methods for rock characterization, testing and monitoring: 1974-2006. ISRM, Ankara

Johnston IW (1991) Geomechanics and the emergence of soft rock technology. Aust Geomech 21:3-26

Kanda MJ, Stacey TR (2016) The influence of various factors on the results of stability analysis of rock slopes and on the evaluation of risk. J South Afr Inst of Min Metall 116:1075-1081

Lorig L, Varona P (2004) Numerical analysis. In: Wyllie DC, Mah CW (eds) Rock slope engineering, 4th edn. Spon Press, London

Marinos P, Hoek E (2001) Estimating the geotechnical properties of heteregoeneous rock masses such as flysch. Bull Eng Geol Environ 60:85-92. https://doi.org/10.1007/ s100640000090

Nickmann M, Spaun G, Thuro K (2006) Engineering geological classification of weak rocks. www.geo.tum.de. Accessed 22 June 2016

Oliveira R (1990) Weak rock materials. In: Cripps JC, Coulthard JM, Culshaw MG, Forster A, Hencher SR, Moon CF (eds) The engineering geology of weak rock. Proceedings of the 26th annual conference of the engineering group of the geological society, 9-13 Sept 1990, Leeds. Balkema, Rotterdam, pp 5-15

Ordnance Survey (2017) Digimap 1:50000. http://edina.ac.uk/ digimap. Accessed 7 June 2017

Paraskevopoulou C, Perras M, Diederichs MS, Amann F, Löw S, Lam T, Jensen M (2017) Time-dependent behaviour of brittle rocks based on static load laboratory testing. J Geotech Geol Eng. https://doi.org/10.1007/s10706-0170331-8

Pennington CVL, Evans HM, Foster C (2009) Landslides of the area around chesterfield, geological sheet 112. British Geological Survey, Keyworth

Read J, Stacey P (2009) Guidelines for open pit slope design. CRC Press, Leiden

Richards KS, Reddy KR (2007) Critical appraisal of piping phenomena in earth dams. Bull Eng Geol Environ 66:381-402

Rocscience (2017) Online tutorials and knowledge base. www. rocscience.com. Accessed 10 July 2017
Smith EG, Rhys GH, Eden RA (1967) Geology of the country around Chesterfield, Matlock and Mansfield-explanation of one-inch Geological Sheet 112. Geological Survey of Great Britain, London

Spink TW, Norbury DR (1990) The engineering geological description of weak rocks and over consolidated soils. In: Cripps JC, Coulthard JM, Culshaw MG, Forster A, Hencher SR, Moon CF (eds) The engineering geology of weak rock. Proceedings of the 26th annual conference of the engineering group of the geological society, 9-13 Sept 1990, Leeds. Balkema, Rotterdam, pp 289-302

Starfield AM, Cundall PA (1988) Towards a methodology for rock mechanics modelling. Int $\mathrm{J}$ Rock Mech Min 25(3):99-106

Stenebraten JF, Fjaer E (2009) Measuring static and dynamic moduli as functions of stress for a weak sandstone. In: 43rd US rock mechanics symposium and 4th U.S.-Canada rock mechanics symposium, 28 June-1 July 2009, Asheville. www.onepetro.org. Accessed 1 Aug 2017

Szczepanik Z, Milne D, Hawkes C (2007) The confining effect of end roughness on unconfined compressive strength. In: 1st Canada-U.S. rock mechanics symposium, 27-31 May, Vancouver. www.onepetro.org. Accessed 20 Aug 2017

Tye AM, Lawley RL, Ellis MA, Rawlins BG (2011) The spatial variation of weathering and soil depth across a Triassic sandstone outcrop. Earth Surf Proc Land 36:569-581

Waltham T (2009) Foundations of engineering geology, 3rd edn. Spon Press, London

Whitworth LJ, Turner AJ (1989) Rock socket piles in the Sherwood Sandstone of central Birmingham. In: Burland JB, Mitchel JM (eds) Piling and deep foundations. Proceedings of the international conference on piling and deep foundations, 15-18 May 1989, London. https://books. google.co.uk. Accessed 17 Aug 2017

Wyllie DC, Mah CW (2004) Rock slope engineering, 4th edn. Spon Press, London

Yagiz S (2011) Correlation between slake durability and rock properties for some carbonate rocks. Bull Eng Geol Environ $70: 377-383$

Yates PGJ (1992) The material strength of sandstones of the Sherwood Sandstone Group of north Staffordshire with reference to microfabric. Q J Eng Geol 25:107-113 